\title{
Addressing Industrial Waste Heat Supply Variability With Organic Rankine Cycle Systems Incorporating Thermal Energy Storage
}

\section{Bipul Krishna Saha}

Indian Institute of Technology Kharagpur

Basab Chakraborty ( $\sim$ basab@see.iitkgp.ernet.in )

Indian Institute of Technology, Kharagpur https://orcid.org/0000-0002-8444-7402

\section{Rohan Dutta}

Indian Institute of Technology Kharagpur

\section{Research Article}

Keywords: Low- grade waste heat, Power generation, Organic Rankine Cycle, Working fluids, Thermoeconomic analysis, Aspen Hysys ${ }^{\circledR}$

Posted Date: July 7th, 2021

DOI: https://doi.org/10.21203/rs.3.rs-658624/v1

License: (9) This work is licensed under a Creative Commons Attribution 4.0 International License. Read Full License 


\title{
Addressing industrial waste heat supply variability with organic Rankine cycle systems incorporating thermal energy storage
}

\author{
Bipul Krishna Saha ${ }^{1}$, Basab Chakraborty ${ }^{1}$, Rohan Dutta $^{2}$ \\ ${ }^{1}$ Rajendra Mishra School of Engineering Entrepreneurship, Indian Institute of Technology, Kharagpur, Paschim Medinipur, \\ West Bengal, India-721302 \\ ${ }^{2}$ Cryogenic Engineering Centre, Indian Institute of Technology, Kharagpur, Paschim Medinipur, West Bengal, India-721302
}

\begin{abstract}
Industrial low-grade waste heat is lost, wasted and deposited in the atmosphere and is not put to any practical use. Different technologies are available to enable waste heat recovery, which can enhance system energy efficiency and reduce total energy consumption. Power plants are energy-intensive plants with low-grade waste heat. In the case of such plants, recovery of low-grade waste heat is gaining considerable interest. However, in such plants, power generation often varies based on market demand. Such variations may adversely influence any recovery system's performance and the economy, including the Organic Rankine Cycle (ORC). ORC technologies coupled with Cryogenic Energy Storage (CES) may be used for power generation by utilizing the waste heat from such power plants. The heat of compression in a CES may be stored in thermal energy storage systems and utilized in ORC or Regenerative ORC (RORC) for power generation during the system's discharge cycle. This may compensate for the variation of the waste heat from the power plant, and thereby, the ORC system may always work under-designed capacity. This paper presents the thermo-economic analysis of such an ORC system. In the analysis, a steady-state simulation of the ORC system has been developed in a commercial process simulator after validating the results with experimental data for a typical coke-oven plant. Forty-nine different working fluids were evaluated for power generation parameters, first law efficiencies, purchase equipment cost, and fixed investment payback period to identify the best working fluid.
\end{abstract}

Keywords: Low- grade waste heat, Power generation, Organic Rankine Cycle, Working fluids, Thermo-economic analysis, Aspen Hysys ${ }^{\circledR}$.

\section{Introduction}

The waste heat energy released into the atmosphere is a critical source of clean, fuel-free, and cheap electricity (Sarkar and Bhattacharyya 2015a). A significant number of WHR approaches are available in the literature at present, such as Brayton Cycle (BC), Sterling Engine (SE), Kalina Cycles (KC), carbon dioxide transcritical cycles, Organic Rankine Cycle (ORC), Steam Rankine Cycle (SRC), Thermo-photovoltaic system and Thermoelectric Generator (TEG) (Desai and Bandyopadhyay 2015b). 
With increasing energy demand, greater use of industrial waste heat and renewable energy sources has become necessary due to the scarcity of fossil fuels and greenhouse gas emission (GHG) emanating from fossil fuel-based thermal power plants (Henriques and Catarino 2016)(Desai and Bandyopadhyay 2015b). This necessitates an evaluation of the potential of such sources for power generation. The selection of the right industrial process is one of the critical issues for waste heat recovery, which can take a leading role in the present era for reducing the carbon footprint (Sikdar et al., 2017). In the Paris climate change summit, the world pledged to reduce GHG by 55\% while moving towards cleaner heat sources, increasing energy efficiency and reusing the unutilized waste heat (European Commission 2018) (Markides 2015) (Bandyopadhyay and Desai 2015).

Sources like geothermal, solar thermal, biogas, and industrial waste heat are significant energy sources capable of contributing substantially to India's electricity demand (Sadeghi and Kalantar 2015)(Desai and Bandyopadhyay 2015a). Reusing low-grade waste heat can reduce costs and save commercial, institutional, and industrial facilities (Rezvani et al., 2015). The Organic Rankine cycle (ORC) is a promising technology that can minimize global environmental pollution, reduce energy consumption, and enhance thermal energy efficiency by utilizing low and medium-grade waste heat (Roy et al., 2011a). Industrial adoption of ORC technology is essential, as it can lead to improved energy efficiency, mitigate energy price hikes, protect the environment by reducing GHG and reduce primary energy consumption (Roy et al. 2011a) (Sikdar et al. 2017). ORC works on low and medium-grade temperature ranges using different types (dry, wet, and isentropic) of working fluids, including refrigerants and hydrocarbons for power generation (Sarkar and Bhattacharyya 2015b). A plant's economy is directly dependent on the proper selection of the working fluid (Minea 2014). We need to estimate the recovery potential and the corresponding thermodynamic cycles for power generation in different industrial sectors.

In many establishments, such as the manufacturing industry, industrial and residential buildings, power plants and transport systems, excess heat is present in vast amounts (Parrondo et al. 2012). When the excess heat temperature exceeds $150^{\circ} \mathrm{C}$, power generation from waste heat is generally economically and theoretically feasible. For Waste Heat to Power (WHP) systems, energy-intensive sectors such as steelmaking and cement are acceptable processes (Saha et al. 2020). The fluctuating and intermittent existence of the waste heat source is one of the most significant technical and economic barriers which restrict the implementation of WHP (National Productivity Council 2017). Characteristics of fluctuating heat sources trigger problems in their usage. Majorly. the low-quality fluctuating heat sources do not allow one to align the properties of waste heat release and heat demand in the manufacturing sector (Islam et al., 2018). As the power plant runs under fluctuating conditions, this energy system must adapt to changing heat supply conditions. To respond to changes in heat supply conditions, serial device monitoring is also needed. The combination of heat storage systems may be feasible to increase thermal 
resource input for power plants. These systems are planned to be used in different industries for waste heat recovery and storage (Dutta et al., 2017a) (Desai and Bandyopadhyay 2016).

Energy Storage Systems (ESS) store surplus energy during low-demand times and produce high demand for electrical energy (Dutta et al. 2017b). Compressed Air Energy Storage needs high-pressure air energy storage, needing a relatively large and expensive pressure tank. In comparison, Cryogenic Energy Storage stores liquefied air, significantly limiting storage capacity requirements. One of CES's key challenges is cost, mainly in the liquefaction process (Agamah and Ekonomou 2017). On the other hand, one of the foremost challenges in the power generation sector is to reduce the gap between generation rates and the demands of power (Shin-Ichi Inage 2009). Large energy storage systems at the level of grid-scale are the suggested methods to meet this challenge. Cryogenic Energy Storage (CES) systems, as shown in the block diagram in Figure 1, are considered as one of the alternatives for largescale energy storage devices (Ding et al. 2016) (Dutta et al., 2017a) (Priya and Bandyopadhyay 2013). These systems use excess power during low demand from the grid to liquefy air and store the liquefied air for later use. This is called the charging process of the CES system. Subsequently, when the power generation is lower than the market demand, this stored liquid evaporates and superheated to an appropriate temperature and expands in turbines to produce power. This is called the discharging process of the CES system. Such a system's advantages over other existing technologies like pumpedhydro and compressed air energy storage systems are scalability, the ability to be location independent, clean, and sustainable with virtually no cost for working fluid (Ding et al. 2016). However, to date, this system has exhibited low turnaround efficiency compared to the other storage systems.

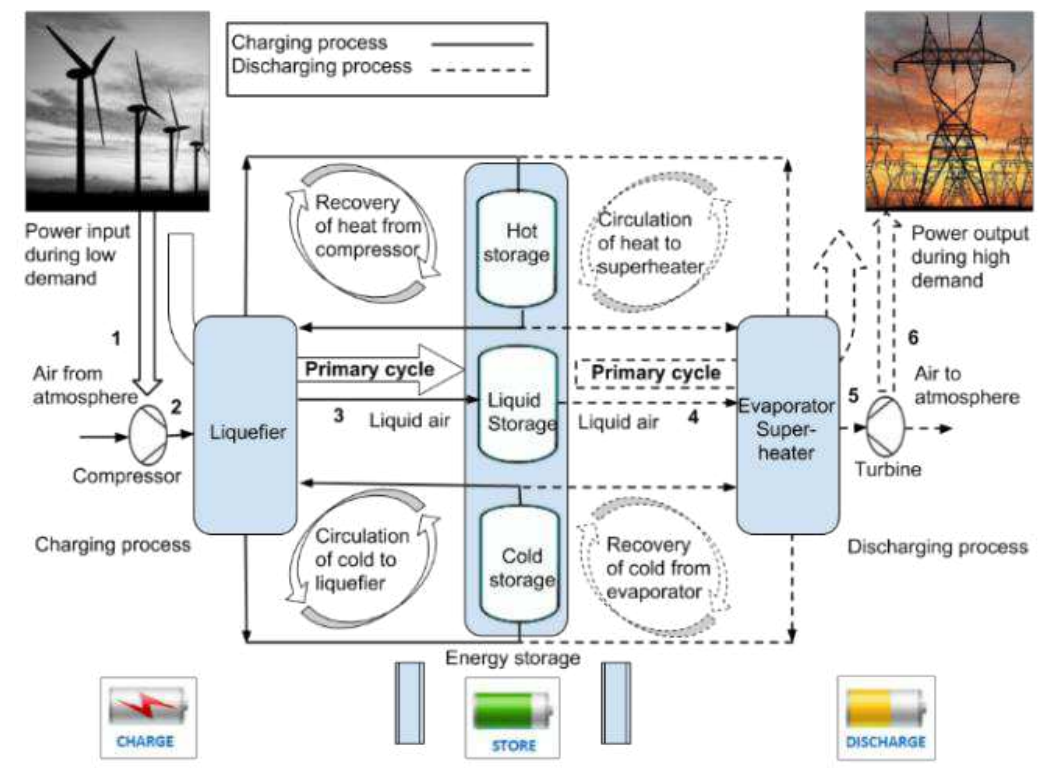

Figure 1. Block diagram of a typical CES system with cold and heat of compression recovery

Recovery of the heat of compression and refrigeration with the high-pressure stream in the evaporatorsuper heater in the power cycle or the discharging process, as shown in Figure 2, has been suggested to 
increase this efficiency (Morgan et al., 2015). The heat of compression may be stored in a thermal energy storage system, and during the discharging process, it may be used as heat duty in an Organic Rankine Cycle (ORC) to produce power (Tafone et al. 2017). The process flowsheet of a typical compression stage with thermal storage and ORC system is shown in Figure 2.

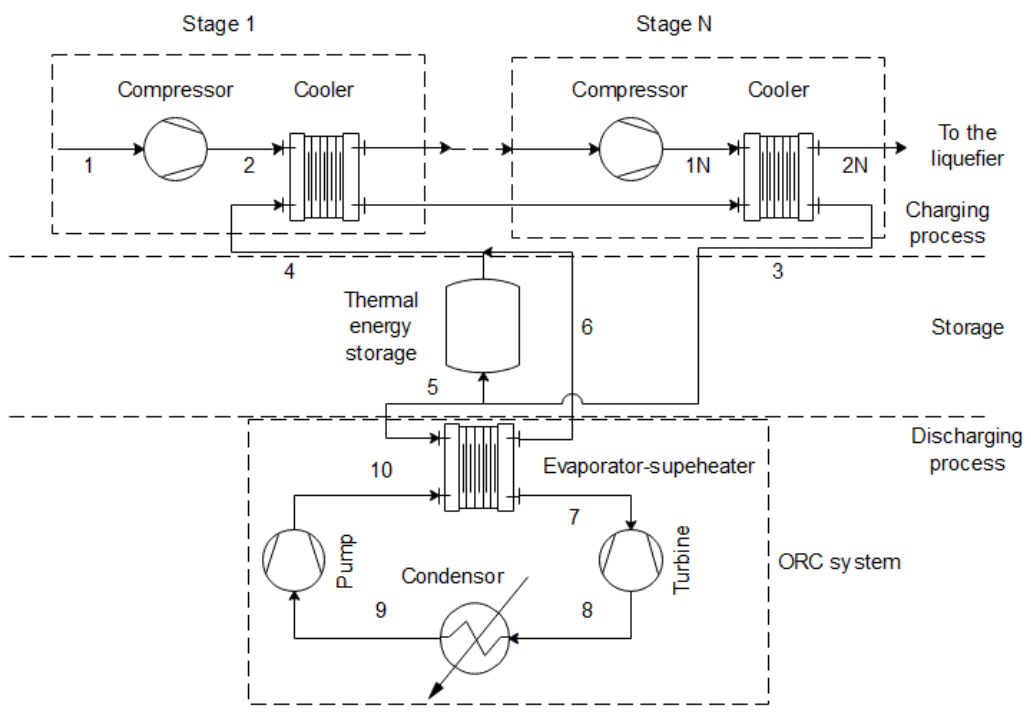

Figure 2. Proposed compression stage of a typical CES system with thermal energy storage and ORC system for utilization of heat of compression

On the other hand, there is no literature, till date, which has dealt with an industry-based analysis of waste heat to generate power in India. From a practical viewpoint, a significant amount of low-grade heat is wasted in industry. If appropriate technological solutions could be incorporated, there is sufficient energy recovery from the industrial sector. This paper presents a thorough case study on ORC and RORC systems for waste heat recovery from an existing Coke Oven plant by investigating and identifying optimal parameters like working fluid, power generation, economy, etc., in the same plant.

\subsection{Overview of waste heat sources}

In this section, energy-intensive manufacturing processes and IC engines in the transport industry are identified as the most suitable waste heat sources for power generation. Both these sources undergo variations in the thermal power available. Figure 3 provides an overview of new techniques for dealing with the heterogeneity of waste heat thermal energy sources available to WHP systems, focused on SRC and ORC power plants. Waste heat temperatures in various processes with temperature levels and waste heat fluctuation characteristics are shown in the Appendix (Table A.1). 


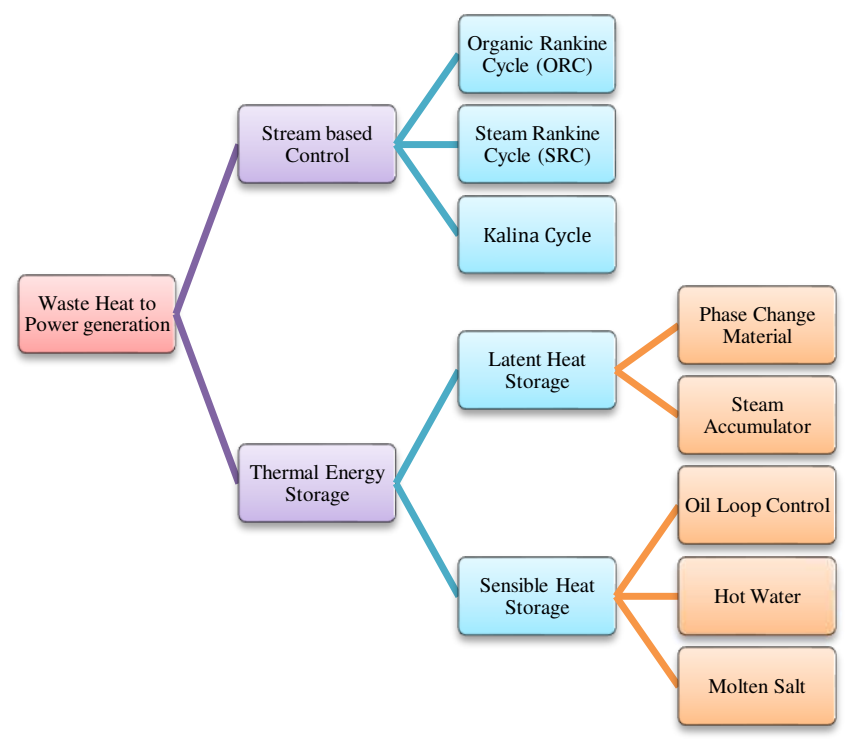

Figure 3. Present essential methods for processing thermal waste heat to power generation (Jiménez-Arreola et al. 2018).

\section{a) Industrial waste heat}

Steelmaking is one of the most energy-intensive industries whose operations emit considerable waste heat. Variations influence dry coke quenching, electric arc furnace (EAF) and billet heating processes in the heat required for recovery. In the cement industry, clinker cooling waste heat is especially suitable for power generation. Other note-worthy waste heat-producing applications include the manufacturing sectors of glass, ceramics and non-ferrous metals (Saha et al. 2020) (Krishna and Basab 2016).

\section{b) Internal combustion (IC) engine generated waste heat}

Ships, trains and long-haul trucks constitute relevant applications for WHP equipped with an IC engine as the main heat source. In road vehicles, the variations in the IC engine's capacity and the different driving conditions determine the available waste heat power (Acar and Dincer 2018).

\subsection{Objective and scope of the study}

The specific objectives are as follows:

I. Investigate the amount and the temperature of the compression heat in a four-stage compressor for a typical CES system.

II. To validate Aspen Hysys ${ }^{\circledR}$ as a process simulator for ORC-based power-generating system under steady-state conditions using an existing plant's actual operational data.

III. To identify the most appropriate working fluid and ORC configuration for low-grade waste heat recovery from the industry. 


\section{Methodology}

\subsection{Process configuration for CES system}

It is found that the Claude cycle as a liquefier is optimum for the power output of the CES system to the input required to drive the compressors in the liquefier (Xie et al., 2019). Therefore, a $1 \mathrm{MW} / 12$ MWh CES energy storage system based on Claude cycle as liquefier has been considered in this study. A typical process flowsheet for Claude cycle-based CES system without the cold and heat of compression recovery in system and power generation cycle using the ORC system is shown in Figure 4.

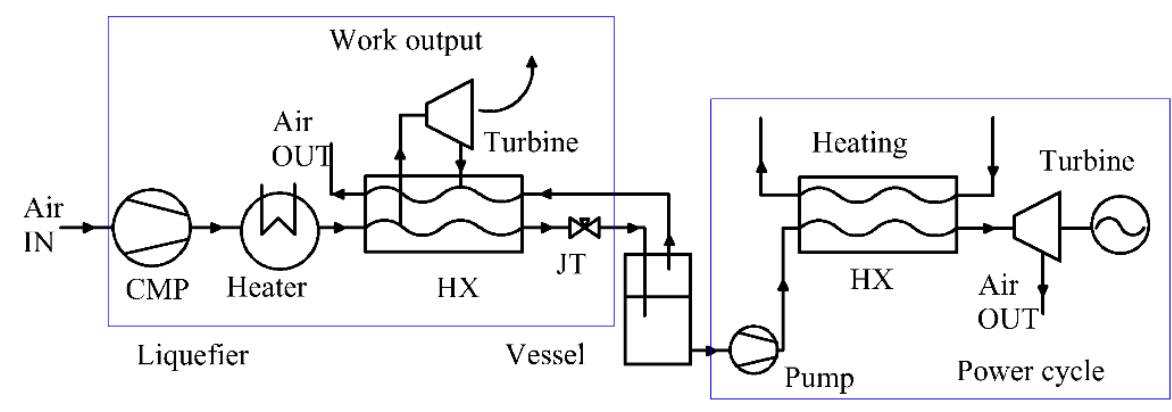

Figure 4: Process configuration of the Claude cycle based CES system considered for this study

\subsection{Types of the working fluid used in the simulation}

Initially, 49 potential working fluids were selected for preliminary calculation, out of which eight topperforming working fluids were selected for the case study based on genetic algorithm optimization, which is discussed in a later section. The displayed Figure 5 shows the selected working fluids.

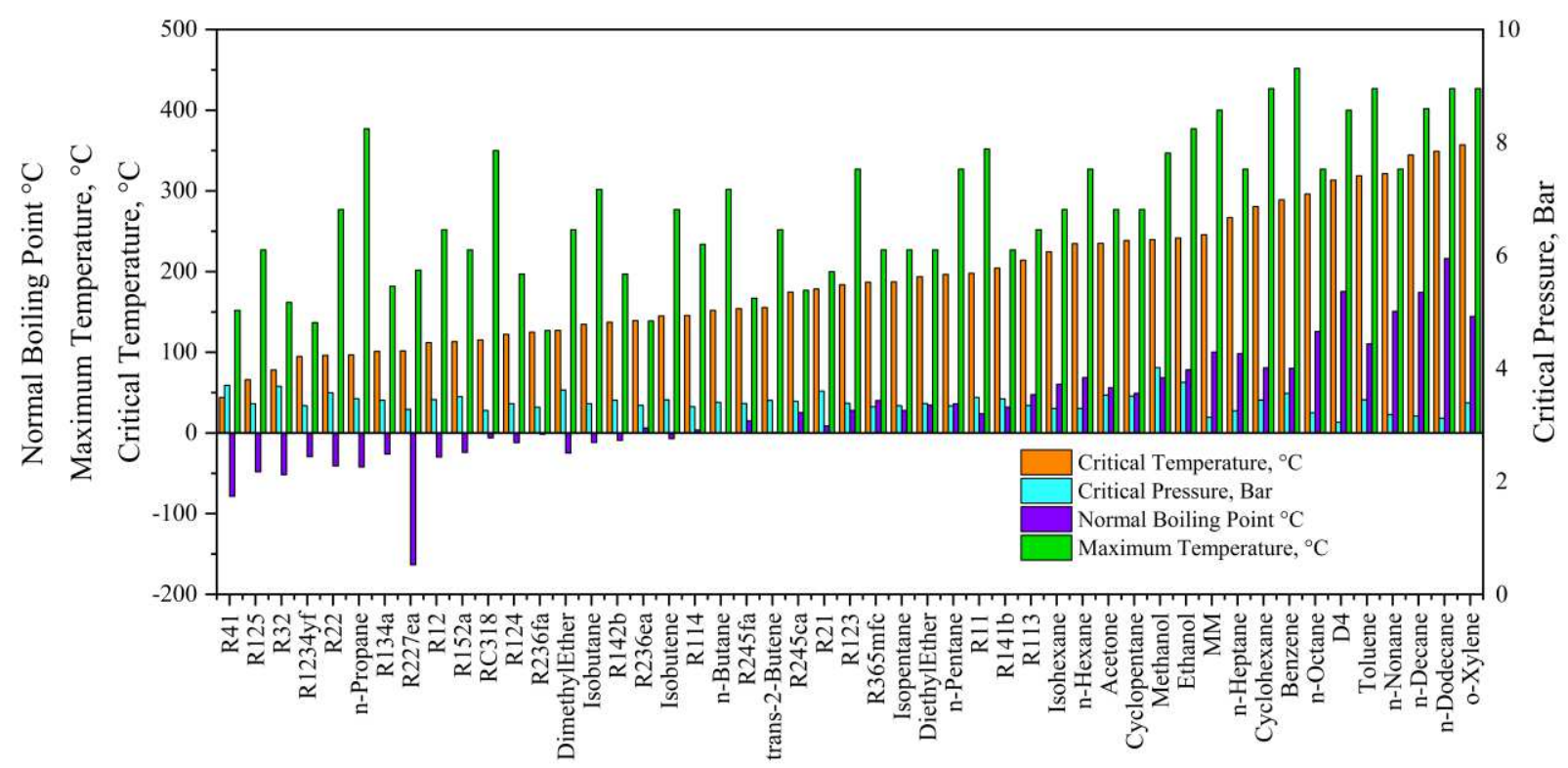

Figure 5. List of $\mathbf{4 9}$ working fluids for ORC application shorted from lower to higher critical temperature. 


\subsection{Optimization of working fluid selection}

In this study, the non-dominated sorting genetic algorithm (NSGA-II) (Deb et al., 2002) has been applied for multi-objective optimization of thermodynamic performance and economic analyses of the selected working fluids. NSGA-II has been applied as:

(1) A fast-non-dominating sorting algorithm to simplify the computation while preserving the parent population's elite members.

(2) Crowding distance-based comparison to ensure evenly distributed solution points on the Pareto frontier.

The general form of the objective function is expressed as:

$$
\left\{\begin{array}{cc}
V-\min f(x)=\left[f_{1}(x),\right. & \left.f_{2}(x), \ldots \ldots, f_{n}(x)\right]^{T} \\
\text { s.t. } & x \in X \\
& X \subseteq R
\end{array}\right\}
$$

where $x$ represents the decision variables vector, $R$ represents the constraints, and $V$-min denotes obtaining the minimum of the multi-objective function vector $f(x)$. If the solution $x_{1} \in X$ is more optimal than all the other solutions in $X$, then $x_{1}$ is reflected as the Pareto optimal solution.

Here, the minimum LEC and maximum EXE are obtained by the following objective function:

$$
\psi=\left\{\begin{array}{l}
\text { minimum LEC }\left(T_{\text {Eva }}, T_{\text {Superheat }}, \dot{m}_{w f}, T_{\mathrm{HS} \mathrm{Out}}, \mathrm{T}_{\mathrm{CS} \text { out }}\right) \\
\text { maximum } \operatorname{EXE}\left(T_{\text {Eva }}, T_{\text {Superheat }}, \dot{m}_{w f}, T_{\mathrm{HS} \text { Out }}, \mathrm{T}_{\mathrm{CS} \text { out }}\right)
\end{array}\right\}
$$

It may be noted from Eq. 2 that the above objective function depends on various physical parameters of the ORC systems. Therefore, five different decision-making variables have been selected: evaporation temperature $\left(T_{\text {Eva }}\right)$, superheating $\left(T_{\text {Superheat }}\right)$, working fluid mass flow rate $\left(\dot{m}_{w f}\right)$, heating

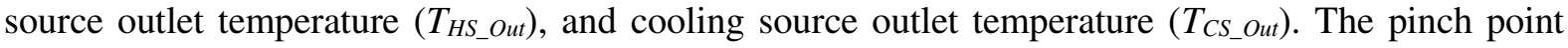
temperature differences at the evaporator and condenser inlet are taken at $4{ }^{\circ} \mathrm{C}$. To determine the optimal compromise solutions on the Pareto frontier, a normalized weighted score is evaluated for every point, and selection is weighted on lower LEC values.

This study was performed in MATLAB (The MathWorks Inc 2018). The working fluids properties (i.e., temperatures, pressures, and enthalpies) of the simple Rankine system are obtained from REFPROP v9.1. The constraints considered during the cycle optimization are shown in

Table 1,

Table 2 and Table 3. 
Table 1. Parameters using in NSGA-II

\begin{tabular}{|l|l|}
\hline Option & Function \\
\hline Population size & 100 \\
\hline Maximum number of generations & 1000 \\
\hline No. of variables & 5 \\
\hline No. of objectives & 2 \\
\hline Crossover type & Intermediate \\
\hline Crossover ratio & 0.8 \\
\hline Crossover fraction & $n_{o} / n_{\text {var }}$ \\
\hline Mutation type & Gaussian \\
\hline Shrink & 0.5 \\
\hline Scale & 0.1 \\
\hline Mutation fraction & $n_{o} / n_{\text {var }}$ \\
\hline
\end{tabular}

Table 2. The parameters used in making the ORC simulation model with NSGA-II

\begin{tabular}{|l|l|l|l|}
\hline Process & Description & Unit of parameter & Parametric value \\
\hline \multirow{2}{*}{$\begin{array}{l}\text { Waste heat } \\
\text { temperature (Evaporator) }\end{array}$} & Inlet & ${ }^{\circ} \mathrm{C}$ & 120 \\
\cline { 2 - 4 } & Outlet & ${ }^{\circ} \mathrm{C}$ & 80 \\
\hline $\begin{array}{l}\text { Water temperature } \\
\text { (Condenser) }\end{array}$ & Inlet & ${ }^{\circ} \mathrm{C}$ & 25 \\
\cline { 2 - 4 } & Outlet & ${ }^{\circ} \mathrm{C}$ & 30 \\
\hline Turbine & Isentropic efficiency & $\%$ & 85 \\
\hline Pump & Isentropic efficiency & $\%$ & 80 \\
\hline Ambient temperature & & ${ }^{\circ} \mathrm{C}$ & 26.7 \\
\hline
\end{tabular}

Table 3. Ranges of decision variables

\begin{tabular}{|l|l|l|l|}
\hline Process & Description & Unit of parameter & Parametric value \\
\hline $\begin{array}{l}\text { Waste heat } \\
\text { temperature }\end{array}$ & Higher limit & ${ }^{\circ} \mathrm{C}$ & 120 \\
\cline { 2 - 4 } & Lower limit & ${ }^{\circ} \mathrm{C}$ & 150 \\
\hline $\begin{array}{l}\text { Cooling source } \\
\text { temperature }\end{array}$ & Higher limit & ${ }^{\circ} \mathrm{C}$ & 30 \\
\cline { 2 - 4 } & Lower limit & ${ }^{\circ} \mathrm{C}$ & 20 \\
\hline $\begin{array}{l}\text { Superheat } \\
\text { Temperature }\end{array}$ & Higher limit & ${ }^{\circ} \mathrm{C}$ & 10 \\
\cline { 2 - 4 } & Lower limit & ${ }^{\circ} \mathrm{C}$ & 5 \\
\hline
\end{tabular}




\begin{tabular}{|l|l|l|l|}
\hline \multirow{2}{*}{$\begin{array}{l}\text { heating source outlet } \\
\text { temperature }\end{array}$} & Higher limit & ${ }^{\circ} \mathrm{C}$ & 60 \\
\cline { 2 - 4 } & Lower limit & ${ }^{\circ} \mathrm{C}$ & 50 \\
\hline $\begin{array}{l}\text { Working fluid mass } \\
\text { flow rate }\end{array}$ & Higher limit & $\mathrm{kg} / \mathrm{s}$ & 2 \\
\cline { 2 - 4 } & Lower limit & $\mathrm{kg} / \mathrm{s}$ & 0.1 \\
\hline
\end{tabular}

\subsection{Validation of process simulation}

This section aims to validate Aspen Hysys ${ }^{\circledR}$ (Aspen Technology, 2016) simulator for small-scale ORC power generation under steady-state operating conditions. The energy efficiency curves and heat input into the ORC evaporator obtained from the Aspen Hysys ${ }^{\circledR}$ simulator have been validated with the original ORC plant-based data (Jing Li 2011).

\subsection{Method of analysis for validation process simulation}

The ORC cycle alternatives of simple ORC and Regenerative ORC (RORC) are analyzed using all the working fluids for the heat of compression generated by the CES system's compression stage with varying numbers of such stages. The process configurations of ORC and RORC cycles and their corresponding $\mathrm{T} \sim \mathrm{s}$ diagrams are shown in Figure 6 and Figure 7. The constraints, which are considered during the cycle optimization, are shown in Table 4. The energy balance and exergy destruction equation for ORC and RORC systems are listed in

Table 5 and Table 6.

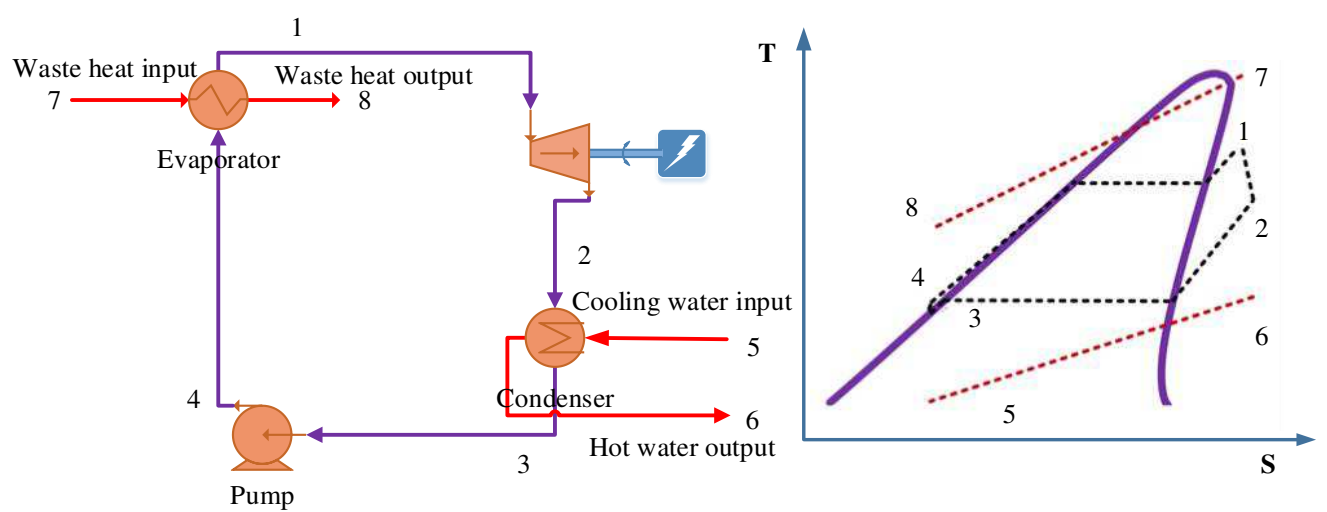

Figure 6. A layout of the ORC simulated in Aspen Hysys®, V9. 


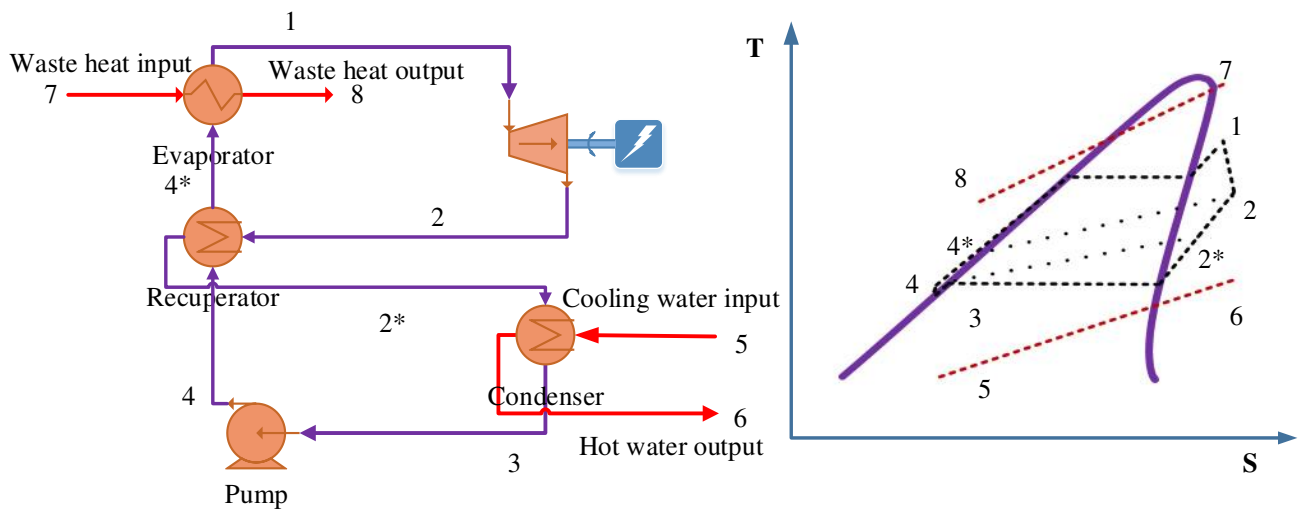

Figure 7. A layout of the regenerative cycle simulated in Aspen Hysys®, V9.

Table 4. The parameter used in making the simulation model in Aspen Hysys.

\begin{tabular}{|l|c|c|c|}
\hline \multicolumn{1}{|c|}{ Parameter } & Value & Parameter & Value \\
\hline Hot fluid & Flue gas & Property package & Peng - Robinson \\
\hline Cold fluid & Water & $\begin{array}{c}\text { Pump inlet temperature } \\
\text { (Working fluid) }\end{array}$ & $75 \%$ \\
\hline $\begin{array}{l}\text { The cold source inlet } \\
\text { temperature }\end{array}$ & $5^{\circ} \mathrm{C}$ & Pump isentropic efficiency & Minimum Approach \\
\hline $\begin{array}{l}\text { Cold source outlet } \\
\text { temperature }\end{array}$ & $30^{\circ} \mathrm{C}$ & Heat exchanger specification & $75 \%$ \\
\hline Cold source pressure & $1500 \mathrm{kPa}$ & Expander isentropic efficiency & Shell and Tube \\
\hline $\begin{array}{l}\text { Pinch temperature in the } \\
\text { condenser }\end{array}$ & $4^{\circ} \mathrm{C}$ & Heat exchanger type & $25 \mathrm{kPa}$ \\
\hline Cold source mass flow rate & Dependent & Heat exchanger pressure drop & Independent \\
\hline $\begin{array}{l}\text { The average temperature in } \\
\text { Kharagpur } \\
\text { (https://en.climate- } \\
\text { data.org/location/2825/) }\end{array}$ & $26.7^{\circ} \mathrm{C}$ & Exhaust gas outlet temperature & Sub Critical \\
\hline Economizer effectiveness & 0.8 & ORC cycles & \\
\hline
\end{tabular}

\subsection{Thermodynamic analysis of the ORC and RORC system}

Eq. (3) shows the external irreversibilities occurring inside the ORC and RORC system (Roy et al. 2010):

$$
\dot{I}=\dot{m} T_{\text {ref }}\left[\sum s_{\text {out }}-\sum s_{\text {in }}+\frac{d s_{s y s}}{d t}+\sum_{k} \frac{q_{k}}{T_{k}}\right]
$$

The heat transferred from all heat sources to the working fluid, and $T_{k}$ refers to the temperature of all heat sources in Kelvin, $\dot{m}(\mathrm{~kg} / \mathrm{s})$ is the total mass flow rate in the cycle, $s$ is entropy state points denoted as a subscript. Subscripts out and in are the output and input, respectively, of the dedicated stream. 
Subscript sys represents the ORC and RORC system, and the subscript ref is represented as the reference temperature. A steady-state of ORC and RORC systems:

$$
\frac{d s_{s y s}}{d t}=0
$$

So, Eq. (3) reduces to:

$$
\dot{I}=\dot{m} T_{\text {ref }}\left[\sum s_{\text {out }}-\sum s_{\text {in }}+\sum_{k} \frac{q_{k}}{T_{k}}\right]
$$

For a steady-state, steady flow system, assuming that there are only one inlet and one outlet for each equipment, Eq. (5) reduces to:

$$
\dot{I}=\dot{m} T_{\text {ref }}\left[\left(s_{\text {out }}-s_{\text {in }}\right)+\frac{q_{k}}{T_{k}}\right]
$$

\begin{tabular}{|c|c|c|c|c|c|}
\hline $\begin{array}{l}\text { Thermodynamic } \\
\text { Process }\end{array}$ & $\begin{array}{l}\text { ORC cycle } \\
\text { component }\end{array}$ & $\begin{array}{l}\text { Energy balance } \\
\text { equations }\end{array}$ & $\begin{array}{l}\text { Equation } \\
\text { Number }\end{array}$ & $\begin{array}{l}\text { Exergy destruction } \\
\text { equations }\end{array}$ & $\begin{array}{l}\text { Equation } \\
\text { Number }\end{array}$ \\
\hline Process, 4-1 & $\begin{array}{l}\text { Shell and } \\
\text { tube heat } \\
\text { exchanger } \\
(\mathrm{E}-100)\end{array}$ & $\dot{Q}_{i}=\dot{m}\left(h_{1}-h_{4}\right)$ & 7 & $\begin{aligned} \dot{I}_{4-1}=\dot{m} T_{\text {ref }}[ & \left(s_{1}-s_{4}\right) \\
+ & \left.+\frac{h_{4}-h_{1}}{T_{H}}\right]\end{aligned}$ & 11 \\
\hline Process, $1-2$ & $\begin{array}{l}\text { Turbo } \\
\text { expander (K- } \\
100)\end{array}$ & $\begin{array}{l}\dot{W}_{T} \\
=\dot{m}\left(h_{1}-h_{2}\right)\end{array}$ & 8 & $\dot{I}_{1-2}=\dot{m} T_{r e f}\left[\left(s_{2}-s_{1}\right)\right]$ & 12 \\
\hline Process, $2-3$ & $\begin{array}{l}\text { Condenser(E- } \\
101)\end{array}$ & $\begin{array}{l}\dot{Q}_{c} \\
=\dot{m}\left(h_{2}-h_{3}\right)\end{array}$ & 9 & $\begin{array}{r}\dot{I}_{2-3}=\dot{m} T_{r e f}\left[\left(s_{3}-s_{2}\right)\right. \\
\left.+\frac{h_{2}-h_{3}}{T_{L}}\right]\end{array}$ & 13 \\
\hline Process, 3-4 & $\begin{array}{l}\text { Working } \\
\text { Fluid Pump } \\
\text { (P-100) }\end{array}$ & $\begin{array}{l}\dot{W}_{p} \\
=\dot{m}\left(h_{3}-h_{4}\right)\end{array}$ & 10 & $\dot{I}_{3-4}=\dot{m} T_{r e f}\left[\left(s_{4}-s_{3}\right)\right]$ & 14 \\
\hline
\end{tabular}

Table 5. Energy balance and exergy destruction equation for ORC system.

\begin{tabular}{|c|c|c|c|c|c|}
\hline $\begin{array}{l}\text { Thermodyn } \\
\text { amic Process }\end{array}$ & $\begin{array}{l}\text { RORC cycle } \\
\text { component }\end{array}$ & $\begin{array}{l}\text { Energy balance } \\
\text { equations }\end{array}$ & $\begin{array}{l}\text { Equation } \\
\text { Number }\end{array}$ & Exergy destruction rates & $\begin{array}{l}\text { Equation } \\
\text { Number }\end{array}$ \\
\hline Process, $4-1$ & $\begin{array}{l}\text { Shell and tube } \\
\text { heat exchanger } \\
(\mathrm{E}-100)\end{array}$ & $\dot{Q}_{i}=\dot{m}\left(h_{1}-h_{4}\right)$ & 15 & $\begin{array}{r}\dot{I}_{4^{*}-1}=\dot{m} T_{r e f}\left[\left(s_{1}-s_{4^{*}}\right)\right. \\
\left.+\frac{h_{4^{*}}-h_{1}}{T_{H}}\right]\end{array}$ & 20 \\
\hline Process, $1-2$ & $\begin{array}{l}\text { Turbo expander } \\
(\mathrm{K}-100) \text {. }\end{array}$ & $\begin{array}{l}\dot{W}_{T} \\
=\dot{m}\left(h_{1}-h_{2}\right)\end{array}$ & 16 & $\dot{I}_{1-2}=\dot{m} T_{r e f}\left[\left(s_{2}-s_{1}\right)\right]$ & 21 \\
\hline Process, $2-3$ & $\begin{array}{l}\text { Condenser (E- } \\
102)\end{array}$ & $\begin{array}{l}\dot{Q}_{c} \\
=\dot{m}\left(h_{4}-h_{3}\right)\end{array}$ & 17 & $\begin{array}{r}\dot{I}_{2^{*}-3}=\dot{m} T_{r e f}\left[\left(s_{3}-s_{2 *}\right)\right. \\
\left.+\frac{h_{2 *}-h_{3}}{T_{L}}\right]\end{array}$ & 22 \\
\hline
\end{tabular}

Table 6. Energy balance and exergy destruction equation for RORC system. 


\begin{tabular}{|l|l|l|l|l|l|}
\hline $\begin{array}{l}\text { Process, }(4- \\
\left.4^{*} \& 2-2^{*}\right),\end{array}$ & $\begin{array}{l}\text { Regenerator } \\
(\text { E-101) }\end{array}$ & $\begin{array}{l}\left(h_{2}-h_{2^{*}}\right) \\
=-\left(h_{4}-h_{4^{*}}\right)\end{array}$ & 18 & $\left(s_{2}-s_{2^{*}}\right)=-\left(s_{4}-s_{4^{*}}\right)$ & 23 \\
\hline Process, 3-4 & $\begin{array}{l}\text { Working Fluid } \\
\text { Pump (P-100) }\end{array}$ & $\begin{array}{l}\dot{W}_{p} \\
=m\left(h_{3}-h_{4}\right)\end{array}$ & 19 & $\dot{I}_{3-4}=\dot{m} T_{r e f}\left[\left(s_{4}-s_{3}\right)\right]$ & 24 \\
\hline
\end{tabular}

The $1^{\text {st }}$ law efficiency is stated as (Roy et al. 2011b):

$$
\eta_{\text {Thermal }}=\left(\frac{\dot{W}_{T}-\dot{W}_{P}}{\dot{Q}_{i}}\right) \times 100
$$

Here, $\dot{W}_{T}$ is work done by the turbine, and $\dot{W}_{P}$ is work done by the pump. $\dot{Q}_{i}$ is the $\mathrm{i}^{\text {th }}$ heat supply in the system. The Figure of merit (FOM) is defined as (Deethayat et al. 2016):

$$
\mathrm{FOM}=\eta_{\text {Thermal }} /\left(1-\frac{T_{L}}{T_{H}}\right)
$$

Here, FOM represents a figure of merit of the total ORC and RORC systems. $T_{L}$ is the cold source temperature, and $T_{H}$ is the heat source temperature.

The exergy of a stream is calculated using the following equation (Dutta et al. 2011):

$$
\dot{E} x_{\text {mass }}=\dot{m}\left[\left(h-h_{r e f}\right)-T_{r e f}\left(s-s_{r e f}\right)\right]
$$

Here ${ }_{\text {mass }}$ is the mass exergy of a stream, $h$ terms are enthalpies at state points denoted as a subscript, and $s$ is entropy at state points denoted as a subscript. The subscript $r e f$ represents the reference temperature.

The exergy balance equation is defined as (Emre and Dincer 2017):

$$
\begin{aligned}
& \sum_{i} \dot{Q}_{i}\left(1-\frac{T_{r e f}}{T_{H}}\right)-\dot{W}+\sum_{i n} \dot{E} x_{\text {mass }}-\sum_{\text {out }} \dot{E} x_{\text {mass }}- \\
& \dot{E} x_{\text {destruction }}=0
\end{aligned}
$$

Here, Ex represents exergy, $\dot{W}$ is work done by the system, and the subscripts in, out, mass and destruction represent input, output, mass exergy, and exergy destruction.

The exergy efficiency of the ORC and RORC cycle is defined as (Emre and Dincer 2017):

$$
\eta_{e x}=\left(\frac{W_{\text {net }}}{\dot{m}\left[\left(h_{\text {in }}-h_{\text {ref }}\right)-T_{\text {ref }}\left(s_{i n}-s_{\text {ref }}\right)\right]}\right) \times 100
$$

Here, $\eta_{e x}$ Represents the exergy efficiency and $W_{\text {net }}$ is the net power output of the system. Subscripts here represent the input of enthalpy and entropy of the system.

\subsection{Economic analysis of the ORC and RORC system}

An economic model (including capital investment, operation, and maintenance cost) of ORC and RORC systems in an industrial plant is discussed in this section. The capital cost is calculated for the major components like the evaporator, regenerator turbine, condenser, and pumps. The constants used in the economic model are shown in 
Table 7. This equipment module costing technique is adapted from (Preißinger et al., 2016), (Özahi et al., 2018), (Dai et al., 2013). The bare module cost of the equipment is given as follows:

$$
C_{b m, X}=C_{p c, X} \cdot F_{b, X}
$$

Where $F_{b, X}$ is the Bare Module Cost factor and is listed in

Table 8. $C_{p c, X}$ denotes the Purchase Equipment Cost and is expressed as follows:

$$
\log _{10} C_{P C, X}=K_{1, X}+K_{2, X} \log _{10} Y+K_{3, X}\left(\log _{10} Y\right)^{2}
$$

$\mathrm{X}=$ Type of equipment, $\mathrm{Y}=$ Heat transfer area of the evaporator, condenser and regenerator, and pump and turbine power capacity. In

Table 8, the equipment cost coefficients $K_{1, X} K_{2, X}$ and $K_{3, X}$ are given (R. Turton, R.C. Bailie 2013).

The total capital cost is as follows:

$$
C_{\text {total }}=\sum C_{b m, X}
$$

The Chemical Engineering Plant Cost Index (I IEPC) accounts for issues caused by inflation (Mignard 2014). The $I_{C E P C}$ values obtained from equipment manufacturers for the years 2001 and 2017 are 397 and 632.5 (Saha et al. 2020). The final capital cost of all the equipment is obtained as:

$$
C_{\text {total }, 2017}=\frac{C_{\text {total }} \cdot I_{C E P C, 2017}}{I_{C E P C, 2001}}
$$

The Capital Recovery Factor (CRF) is obtained as follows:

$$
\mathrm{CRF}=\frac{i(1+i)^{n}}{(1+i)^{n}-1}
$$

where $i=$ interest rate, $n=$ Lifetime of the entire ORC, and RORC system.

The Levelised Energy Cost (LEC) is expressed as follows:

$$
\mathrm{LEC}=\frac{C R F \cdot C_{t o t a l, 2017}+C_{o m}}{N \cdot W_{\text {net }}}
$$

where $C_{o m}=$ The operation and maintenance cost, $N=$ Total plant operation hour in one year 
The Static investment payback period (SIPP) is defined as follows:

$$
\mathrm{SIPP}=\frac{C_{t o t a l, 2017}+C_{o m}}{D_{h r}}
$$

where $D_{h r}=$ the income per hour by recovering the waste heat for power generation and is stated as follows:

$$
D_{h r}=\eta_{\text {Power }} \cdot m_{h s}\left(h_{h i}-h_{h o}\right) \cdot P_{\text {electricity }}
$$

$\eta_{\text {Power }}=$ System efficiency, $P_{\text {electricity }}=$ Cost of electricity

Table 7. Value of constants used in the economic model

\begin{tabular}{|c|c|}
\hline Economic parameter & Value \\
\hline $\mathrm{N}$ & $8000 \mathrm{~h}$ \\
\hline $\mathrm{N}$ & 25 years \\
\hline $\mathrm{I}$ & $5 \%$ \\
\hline$C_{\text {om }}$ & 1.5 \\
\hline$P_{\text {electricity }}$ & $\begin{array}{c}0.342 \mathrm{USD} / \mathrm{kWh} \text { in San Francisco, CA, USA ORC } \\
\text { (Zhang et al. 2018) }\end{array}$ \\
\hline
\end{tabular}

Table 8. The capital cost estimation model with the coefficient (R. Turton, R.C. Bailie 2013).

\begin{tabular}{|l|c|l|l|l|l|}
\hline $\mathrm{X}$ & $\mathrm{Y}$ & \multicolumn{1}{|c|}{$K_{1 . X}$} & \multicolumn{1}{c|}{$K_{2 . X}$} & \multicolumn{1}{c|}{$K_{3 . X}$} & $F_{\text {im.X }}$ \\
\hline Evaporator & $A_{\text {eva }}(m)^{2}$ & 4.3247 & -0.3030 & 0.1634 & 2.9 \\
\hline Condenser & $A_{\text {con }}(m)^{2}$ & 4.3247 & -0.3030 & 0.1634 & 2.9 \\
\hline Turbine & $W_{\text {Turbine }}(k W)$ & 2.7051 & 1.4398 & -0.1776 & 3.5 \\
\hline Pump & $W_{\text {pump }}(k W)$ & 3.3892 & 0.0536 & 0.1538 & 2.8 \\
\hline Regenerator & $A_{\text {reg }}(m)^{2}$ & 4.3247 & -0.3030 & 0.1634 & 2.9 \\
\hline
\end{tabular}

\subsection{Heat Exchanger model in Aspen Hysys}

Aspen Hysys ${ }^{\circledR}$, V9 has been used as a script manager for the thermal properties of heat exchangers for steady-state simulation (Liu and Karimi 2018). The following general relations in Eq. (38) shows,

$$
\text { Balance Error }=\left[\dot{\boldsymbol{m}}_{\text {Cold }}\left(\boldsymbol{h}_{\text {out }}-\boldsymbol{h}_{\text {in }}\right)_{\text {cold }}-\dot{\boldsymbol{Q}}_{\text {leak }}\right]-\left[\dot{\boldsymbol{m}}_{\text {hot }}\left(\boldsymbol{h}_{\text {in }}-\boldsymbol{h}_{\text {out }}\right)_{\text {hot }}-\dot{\boldsymbol{Q}}_{\text {loss }}\right]
$$

Heat leak, heat loss, Balance Error $=$ a Heat Exchanger Specification that equals zero for most applications, hot and cold are the hot and cold fluids, in and out is the inlet and outlet stream.

The total heat transferred between the tube and shell sides (Heat Exchanger duty) can be defined in terms of the overall heat transfer coefficient, the area available for heat exchange and the log mean temperature difference shown in Eq. (39) 


$$
\mathbf{Q}=\mathbf{F}_{\mathbf{t}} \times \mathbf{U} \times \mathbf{A} \times \Delta \mathbf{T}_{\mathbf{L M T D}}
$$

where $\mathrm{U}$ is the overall heat transfer coefficient, $\mathrm{A}$ is the surface area available for heat transfer, $\Delta T_{L M}$ is the natural $\log$ of the mean temperature difference (LMTD), and $F_{t}$ is the LMTD correction factor

The heat transfer coefficient and the surface area are often combined for convenience into a single variable referred to as UA. The LMTD and its correction factor are defined in the Performance section.

\subsection{Expander model in Aspen Hysys}

The expander operation decreases the pressure of a high-pressure inlet gas stream to produce an outlet stream with low pressure and high velocity. An expansion process involves converting the internal energy of the gas to kinetic energy and finally to shaft work. For an expander, the efficiency is given as the ratio of the actual power produced in the expansion process to the power produced for an isentropic expansion: The expressions are given in Eq. (40) and (41):

$$
\begin{aligned}
& \text { Efficiency }(\%)=\frac{(\text { Fluid Power Produced })_{\text {actual }}}{(\text { Fluid Power Produced })_{\text {isentropic }}} \times 100 \% \\
& \text { Adiabatic Efficiency }=\frac{(\text { Work produced })_{\text {actual }}}{(\text { Work produced })_{\text {ideal }}}=\frac{\left(\mathbf{h}_{\text {out }}-\mathbf{h}_{\text {in }}\right)_{\text {actual }}}{\left(\mathbf{h}_{\text {out }}-\mathbf{h}_{\text {in }}\right)_{\text {ideal }}}
\end{aligned}
$$

Where $h$ is mass enthalpy, out is product discharge, in is feed stream, $P$ is pressure, in and out is the inlet and outlet stream.

\subsection{Pump model in Aspen Hysys}

Calculating the ideal power of the pump required to raise the pressure of the liquid: The calculations are based on the standard pump equation for power, which uses the pressure rise, the liquid flow rate, and density:

$$
\text { Power }_{\text {ideal }}=\frac{\left(P_{\text {out }}-P_{\text {in }}\right) \times \text { Flowrate }}{\text { Liquid Density }}
$$

Where $P$ is pressure and in and out is the inlet and outlet stream.

\subsection{Plant configuration and process conditions}

The coke oven plant, an ISO 9001-2008 certified company, was founded in 2007 in Kharagpur, West Bengal, India. BEL has a maximum installed capacity of producing 1.2 million tonnes of coke per annum through its coke oven and a power generation plant, with a maximum capacity of $80 \mathrm{MW}$. The working power production capacity of the combined heat and power (CHP) system in BEL is $40 \mathrm{MW}$, with a coke production capacity of 0.6 million tonnes per annum (MTPA). The details related to the CHP plant are provided in Table 9. The schematic diagram of the actual plant is shown in Figure 8. 


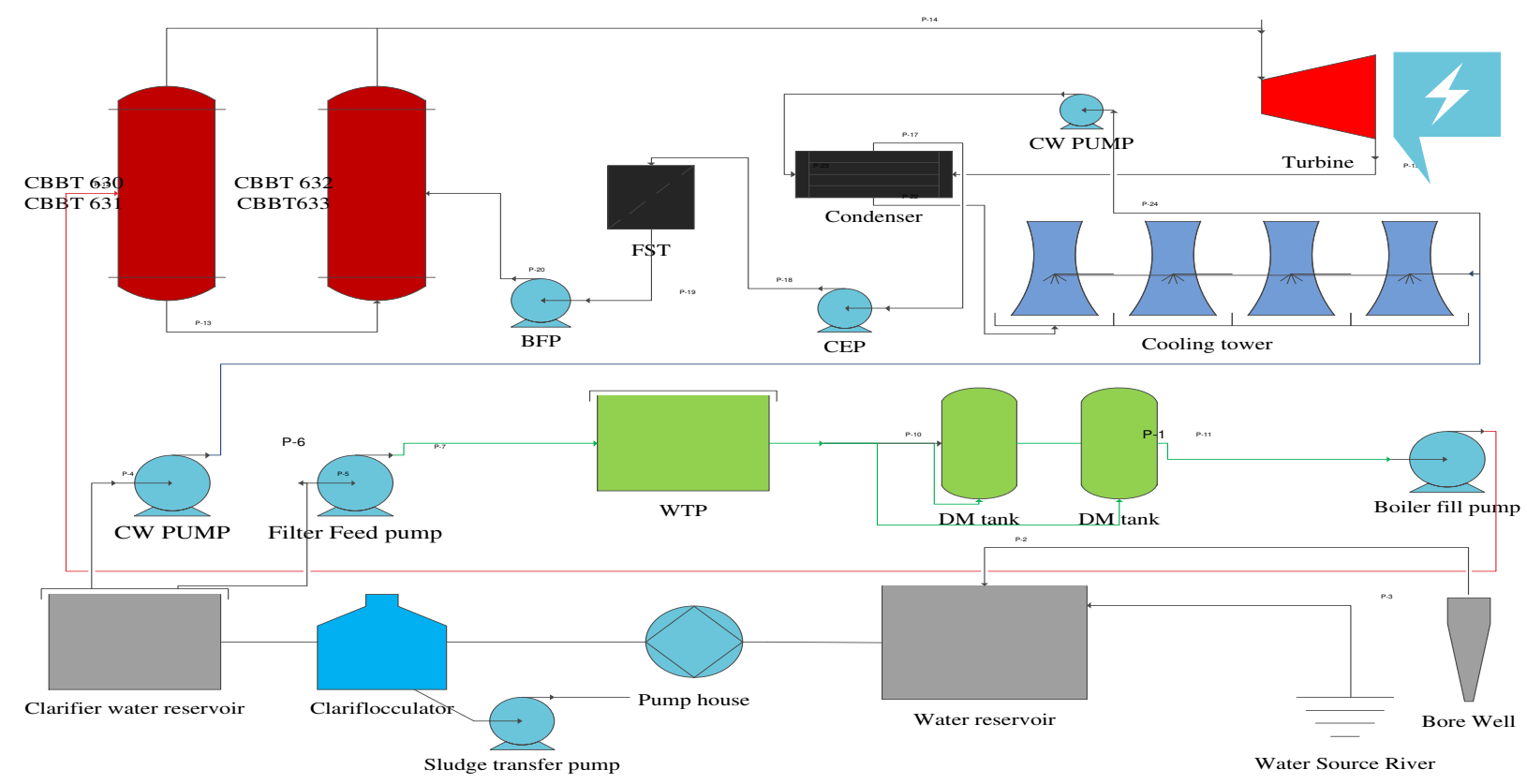

Figure 8. Schematic diagram of the CHP plant in India

Table 9: CHP Plant Details.

\begin{tabular}{|c|c|}
\hline \multicolumn{2}{|l|}{ System details } \\
\hline $\begin{array}{l}\text { Flue gas mass flow rate from coke } \\
\text { oven }\end{array}$ & $95000-110000 \mathrm{~N} \mathrm{~m}^{3} / \mathrm{h} /$ Battery \\
\hline Production time & 24 hour \\
\hline Power used in auxiliary & $7-8 \%$ daily power production \\
\hline Power production generator & The gas turbine, $40 \mathrm{MW}, 11 \mathrm{kVA}$ \\
\hline Type of condenser & Cooling towers, Water-cooled condenser \\
\hline Fuels used & Natural gas \\
\hline ID fan capacity & ID Fan $125 \mathrm{~kW}$ x $4-24$ hour running \\
\hline System cogeneration efficiency & $90 \%$ \\
\hline Local power grid utility & WBSEDCL \\
\hline Waste heat temperature & $180^{\circ} \mathrm{C}$ \\
\hline $\mathrm{SO}_{2}\left(\mathrm{mg} / \mathrm{Nm}^{3}\right)$ & 5.12 \\
\hline $\mathrm{CO}\left(\mathrm{mg} / \mathrm{Nm}^{3}\right)$ & 4.22 \\
\hline $\mathrm{PM}\left(\mathrm{mg} / \mathrm{Nm}^{3}\right)$ & 8.52 \\
\hline $\mathrm{NO}_{\mathrm{x}}\left(\mathrm{mg} / \mathrm{Nm}^{3}\right)$ & $16.63\left(\mathrm{NO}_{\mathrm{x}}\right.$ values are corrected to $15 \%$ Oxygen $)$ \\
\hline
\end{tabular}




\subsection{Building electricity and cooling loads}

The average energy consumption of a commercial building is $61.63 \mathrm{kWh} / \mathrm{day}$, while the average electricity demand value is $20.12 \mathrm{kWh} /$ day to provide the cooling load of a commercial building. The daily energy usage of the commercial building during the year 2017 are shown in Figure 9. Figure 10 shows the average mean daily atmospheric temperature over one year in Kharagpur, West Bengal, India, in hot and humid regions. Figure 11 indicates the required Average system load profile in West Bengal (2019), India, over one year (IIT Kanpur).

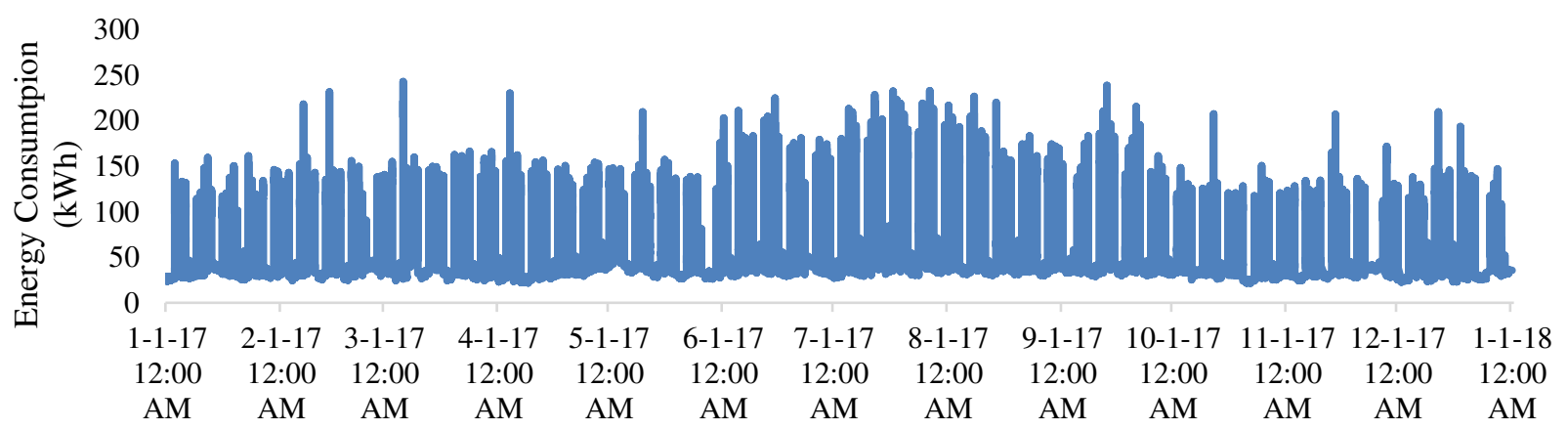

Figure 9. The time-aligned smart meter readings $(\mathrm{kWh})$ the aggregated hourly energy consumption $(\mathrm{kWh})$ for the commercial load.

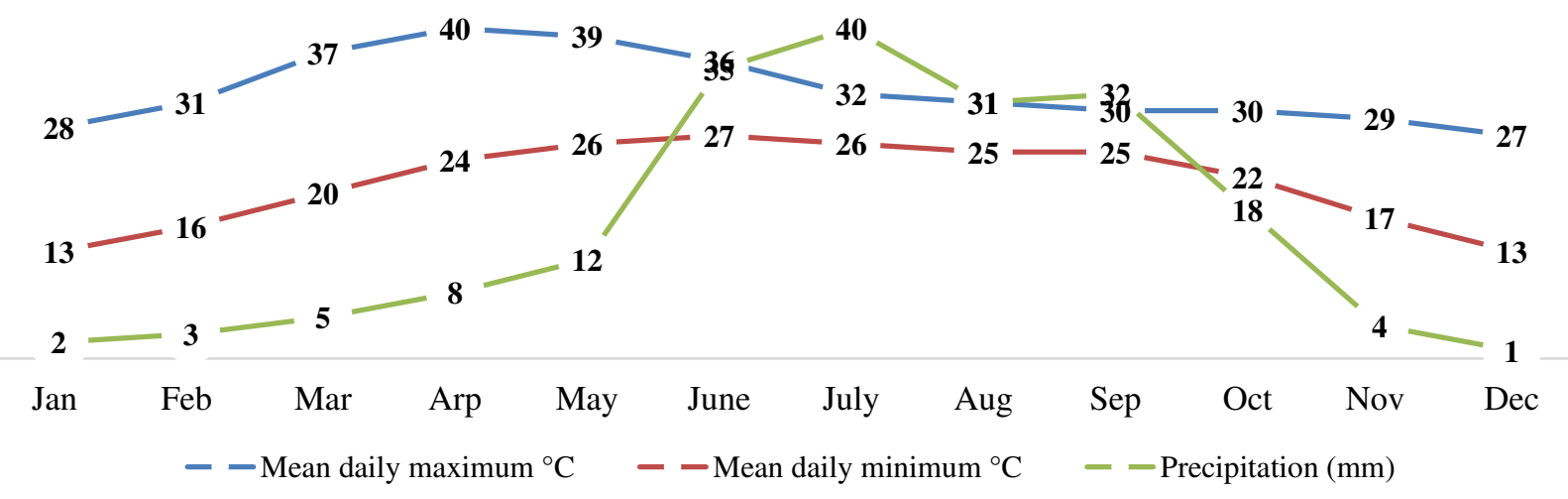

Figure 10. Average mean daily air temperature in hot and humid regions in Kharagpur, West Bengal, India. 


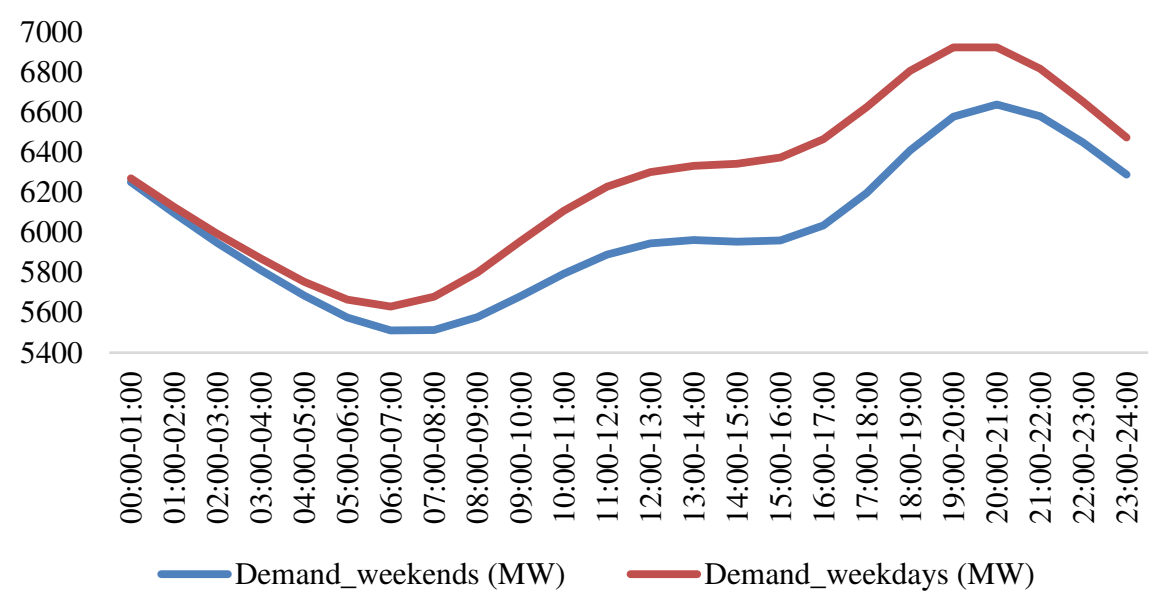

Figure 11. Average system load profile West Bengal (2019), India, over one year.

\section{Result and discussion}

\subsection{Comparison of experimental results with simulation}

Steady-state simulation of ORC has been performed for the condensation operations based on existing plant data; the results were compared to energy efficiency and heat input in the evaporator, as shown in Figure 12 (a) and (b). It has been observed that all the state points and the liquids produce a close match with those of the plant data, which also authenticate estimation of unknown parameters. Assuming the direct cool-down sequence, all the steady-state simulations have been executed. There have been some deviations from simulation, and their causes are listed below.

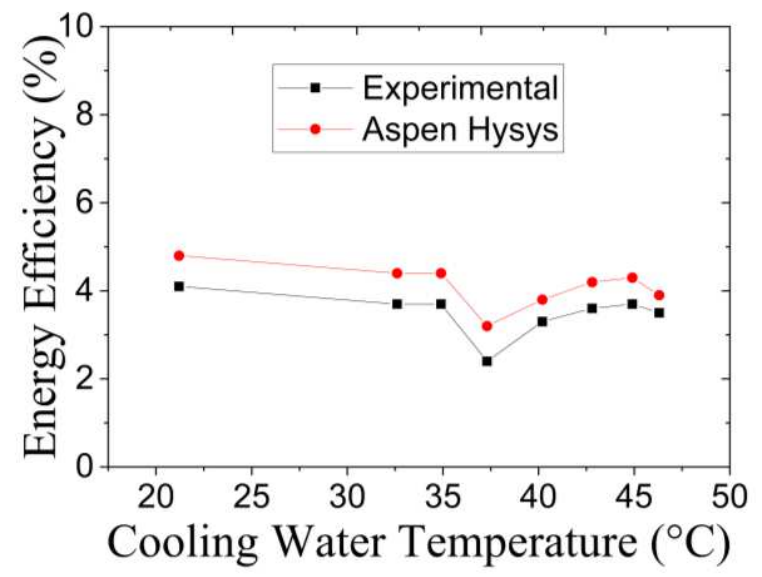

(a)

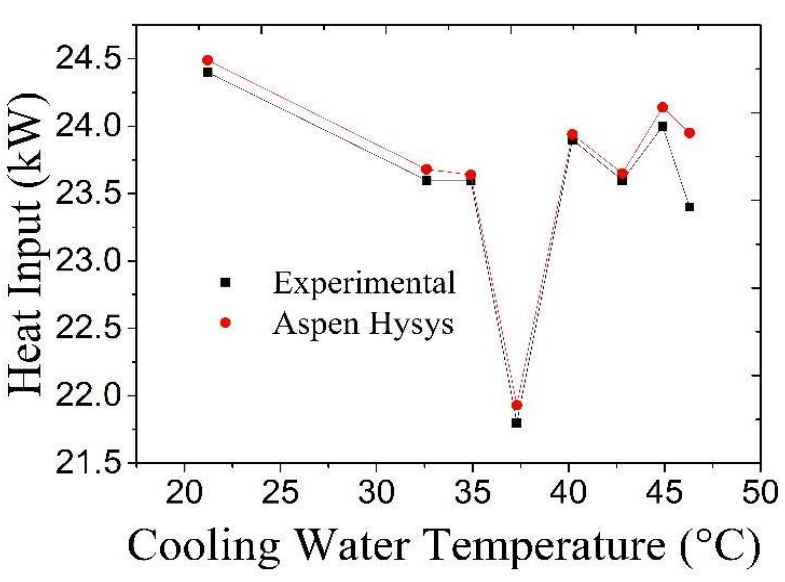

(b)

Figure 12. Validation of energy efficiency and heat input of experimental data with the simulation result. 


\subsubsection{Causes for deviation results in simulation}

The simulation result deviations from actual experimental plant data are a common occurrence and its minimization is the goal of the plant engineer. The main reasons are listed below:

i. The variation of the equipment's material property with respect to temperature has been manually added; this may not be the best option.

ii. The preloaded numerical method used in Aspen Hysys may not deliver accurate results.

iii. The proper order of cool-down operation of the real plant is unknown.

iv. The expander and pump's isentropic efficiency has changed with the generator rotation speed variations and input shaft power.

\subsubsection{Simulation process: Problems arising in Aspen Hysys $®$, V9 and solutions}

Simulation of an ORC system needs the following features requiring assessment for convergence and perfection of the simulation result-selecting relevant Equation of State (EOS) to generate fluid thermodynamic property data.

- Selection of proper transport properties of the working fluids for generating property data.

- Consideration of thermo-physical properties for the insulation and materials.

- Specifications of all the equipment and their performance characteristics.

- Solve the mathematical models of all equipment required in the numerical methods.

- Simple Process flow diagram for reducing the computation time.

\subsection{Process modeling and simulation for the CES system}

Simulation cases for the selected thermodynamic cycles were developed using a commercial process simulator, Aspen Hysys ${ }^{\circledR}$, at steady-state conditions (Dutta et al. 2017a). The Peng-Robinson equation of state was used for the generation of thermodynamic property data in the simulator. The in-built models based on energy balance equations for the equipment in the cycle were used. A detailed discussion of each equipment model for energy and exergy analyses is presented (Dutta et al., 2017a). The evaporator-superheater in the cycle was modeled using the heater model that supplied heat at a constant temperature, simplifying the exergy destruction calculations. Parametric studies were performed using the case study option along with the spreadsheet operation. Exergy destructions in the cycle and individual equipment were calculated based on the simulation results using Microsoft Excel ${ }^{\circledR}$. REFPROP $^{\circledR}$ was used to obtain the enthalpy and entropy data for all the fluids. To keep the references similar for thermodynamic properties such as enthalpy, entropy, etc., in the calculations, those property data were estimated using either the simulator or REFPROP ${ }^{\circledR}$. The flowsheet was built based on the following assumptions:

1. No pressure drops across the heat exchangers, heater and coolers.

2. Adiabatic efficiencies of compressors, pumps, and turbines are $75 \%$.

3. No heat in-leak in any equipment. 
4. $100 \%$ generator efficiencies.

5. Charging and discharging times are the same.

6. Storage of refrigerants was not considered.

7. No piping and valves were considered in the flowsheet.

8. $5^{0} \mathrm{C}$ temperature approach was considered in the thermal energy storage system with $80 \%$ storage efficiency.

\subsection{The heat of compression generated during the compression of air in the CES system}

The compression stage generally consists of compressors and inter/after coolers. During system charging, the power is input only to increase the atmosphere's air pressure after filtration. During compression of air, heat is generated due to the isentropic operation of the compressor. This heat is dissipated in the atmosphere via cooling using water or air. This, therefore, leads to high exergy destruction in the liquefier (Thomas 2012). The attempt was made to determine the heat of compression and the temperature at the compressor's outlet for using this heat to produce power using the ORC/RORC cycle.

It is known that with an increasing number of stages of compression, the specific power required in the compressor reduces, as may be seen in Figure 13 (a) and Figure 13 (b) (Thomas 2012). This eventually reduces the outlet temperature of the compressor and the heat of compression in the process. The parametric study was performed to determine the heat of compression for multi-stage compression. The results are shown in Figure 14.

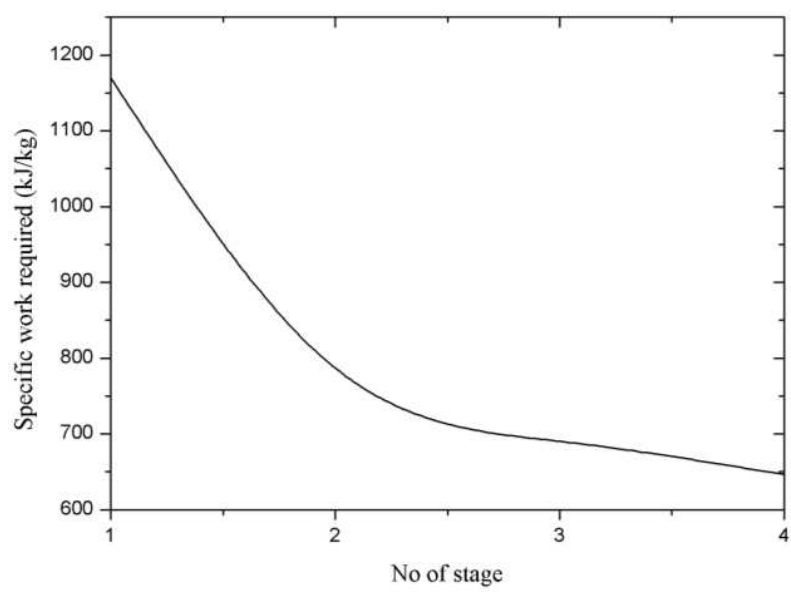

(a)

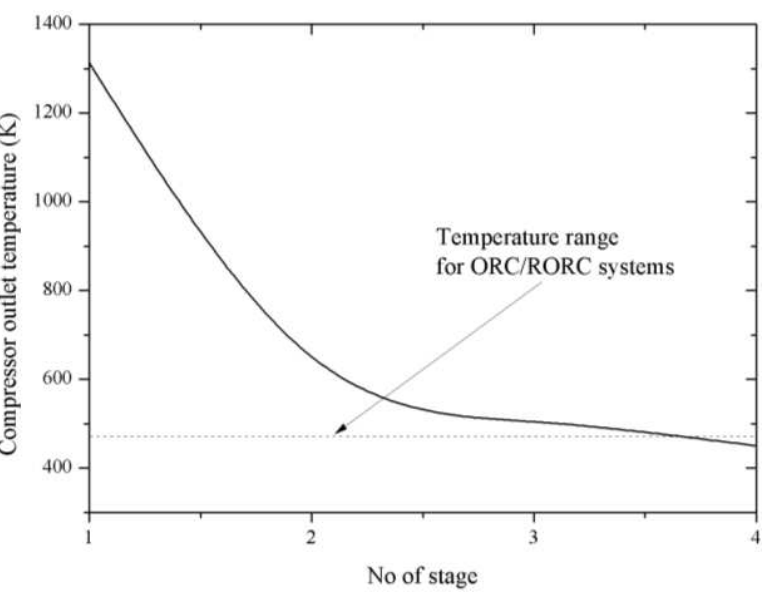

(b)

Figure 13. Variation of specific work required, (b) variation of compressor outlet temperature with a number of compressor stage with outlet pressure of $150 \mathrm{bar}$

It is evident from Figure 14 that the temperature at the outlet of the compressors in four stages of compression is below the typical operating high temperature of an ORC/RORC system. As this system works for low-grade waste-heat, which is waste-heat at a temperature below 2000C, four-stage of compression is the choice of a number of compression stages though it may be observed that the specific 
work required and heat are not far lower for a three-stage compression. Therefore, in this paper, the heat of compression of the four-stage compression stage was used.

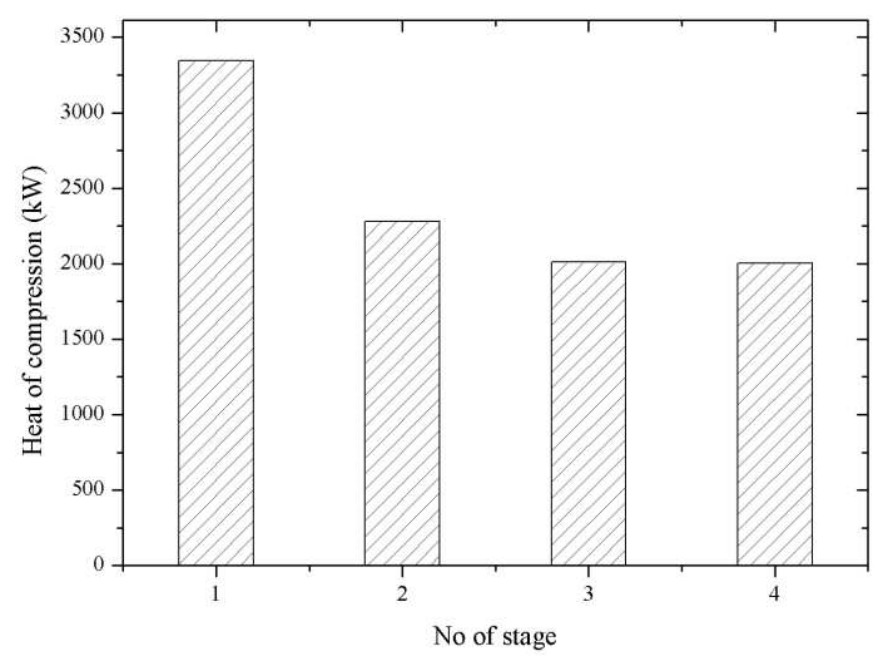

Figure 14. The heat of compression with a number of compression stage in the CES system

The heat of compression with four-stage compression was found to be $2 \mathrm{MW}$ at $450 \mathrm{~K}$ temperature. Therefore, the heat duty for the ORC/RORC cycle was considered as $1.6 \mathrm{MW}$ at $450 \mathrm{~K}$. This is due to fact that the efficiency of heat storage at the thermal energy storage was assumed to be $80 \%$.

\subsection{Optimal compromise solution}

Eight various working fluids, namely Butane, Heptane, Hexane, IsoPentane, Neopentane, R-134a, R$245 \mathrm{fa}$ and Toluene, were carefully screened for their thermodynamic behavior. A multi-objective optimization (MOO) was carried out using an elitist non-dominated sorting genetic sorting algorithm (NSGA-II) for addressing the conflicting behavior of thermodynamic performance (exergy efficiency, EXE) and economic performance (Levelized energy cost, LEC). The MOO studies are conducted for every eight working fluids, and Pareto optimal fronts are generated accordingly. An advanced Pareto ranking method is known as Grey relation analysis (GRA), and entropy information for weighting the objectives is considered to select one optimal solution from the Pareto optimal front. Along with this, an explicit economic performance assessment index, namely the Static Investment Payback Period (SIPP), is considered to decide the most cost-effective working fluid among the considered fluids. Based on the obtained results, it is confirmed that R245fa is the most cost-effective working fluid with the shortest SIPP. Finally, the results suggest that GRA with entropy information considered in this study can be employed for any possible working fluid to recover low-temperature waste heat in the ORC (Saha et al. 2019) (Saha et al. 2020). The results are shown in Appendix Figure. A. 1.

\subsection{The net power output of ORC and RORC}

This work's objective has been to analyze parametrically, compare, and optimize the system power output. This is based on an optimal mass flow rate with respect to waste heat temperature. We observed 
that the power output depends on the working fluid's critical pressure (Roy et al. 2011a). As shown in Figure 15, it was observed that the net power output from the working fluids Butane (18.87 kW, 27.04 $\mathrm{kW})$, Heptane (24.24 kW, $34.03 \mathrm{~kW})$, Hexane (23.30kW, $32.55 \mathrm{~kW})$, Isopentane (19.95 kW,28.18 kW), Neopentane $(16.61 \mathrm{~kW}, 23.75 \mathrm{~kW})$ and Toluene $(27.23 \mathrm{~kW}, 37.69 \mathrm{~kW})$ are comparatively higher for both ORC and the RORC systems; Eqns. (7) and (15) may be referred to in this regard. Further, power output for ORC and RORC of R134a (7.73kW, $11.51 \mathrm{~kW}$, respectively for ORC and RORC) and R245fa $(9.80 \mathrm{~kW}, 13.95 \mathrm{~kW})$ are comparatively lower for both ORC and the RORC systems. The variation in the result may be attributed to changes in enthalpies at the turbine inlet and outlet, with the turbine's isentropic efficiency being maintained at $75 \%$. Nevertheless, the possible reasons behind the reduction of the cycle efficiency of the ORC system could be the following:

1. Limiting pressure at the turbine outlet restricted any further reduction of the ORC cycles' temperatures, leading to an increase in the turbine outlet temperature.
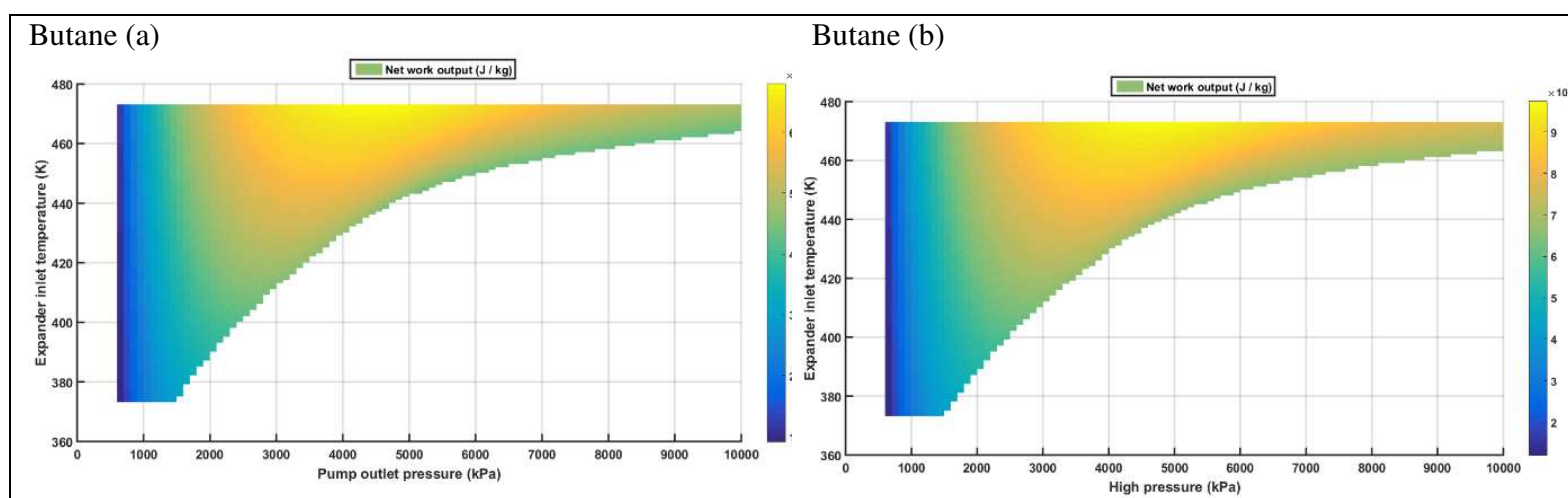

Heptane (a)

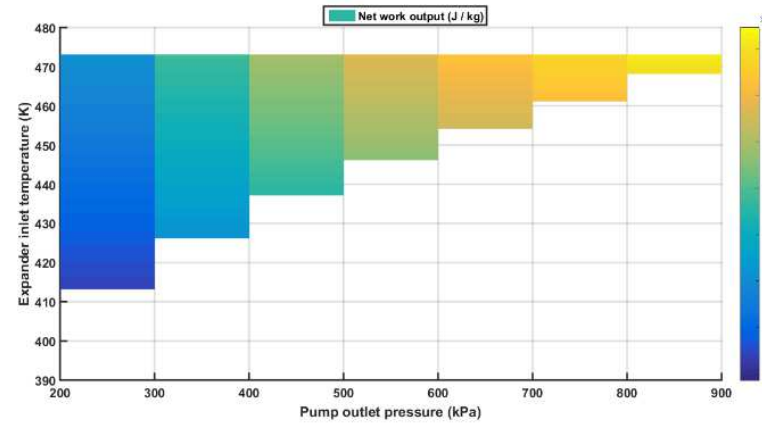

Heptane (b)

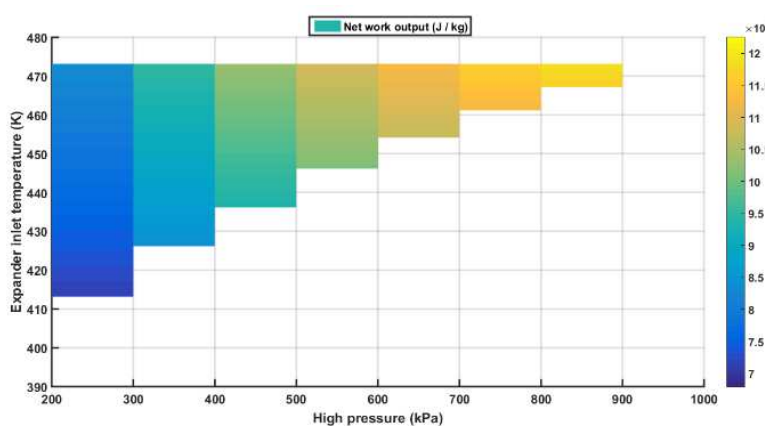

Hexane (a)

Hexane (b)
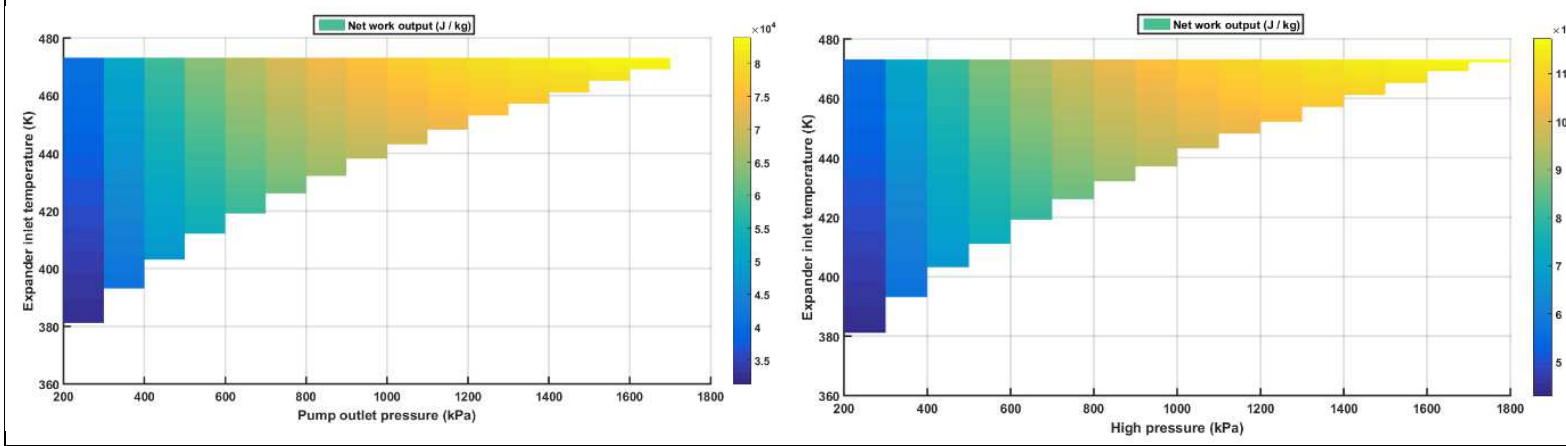

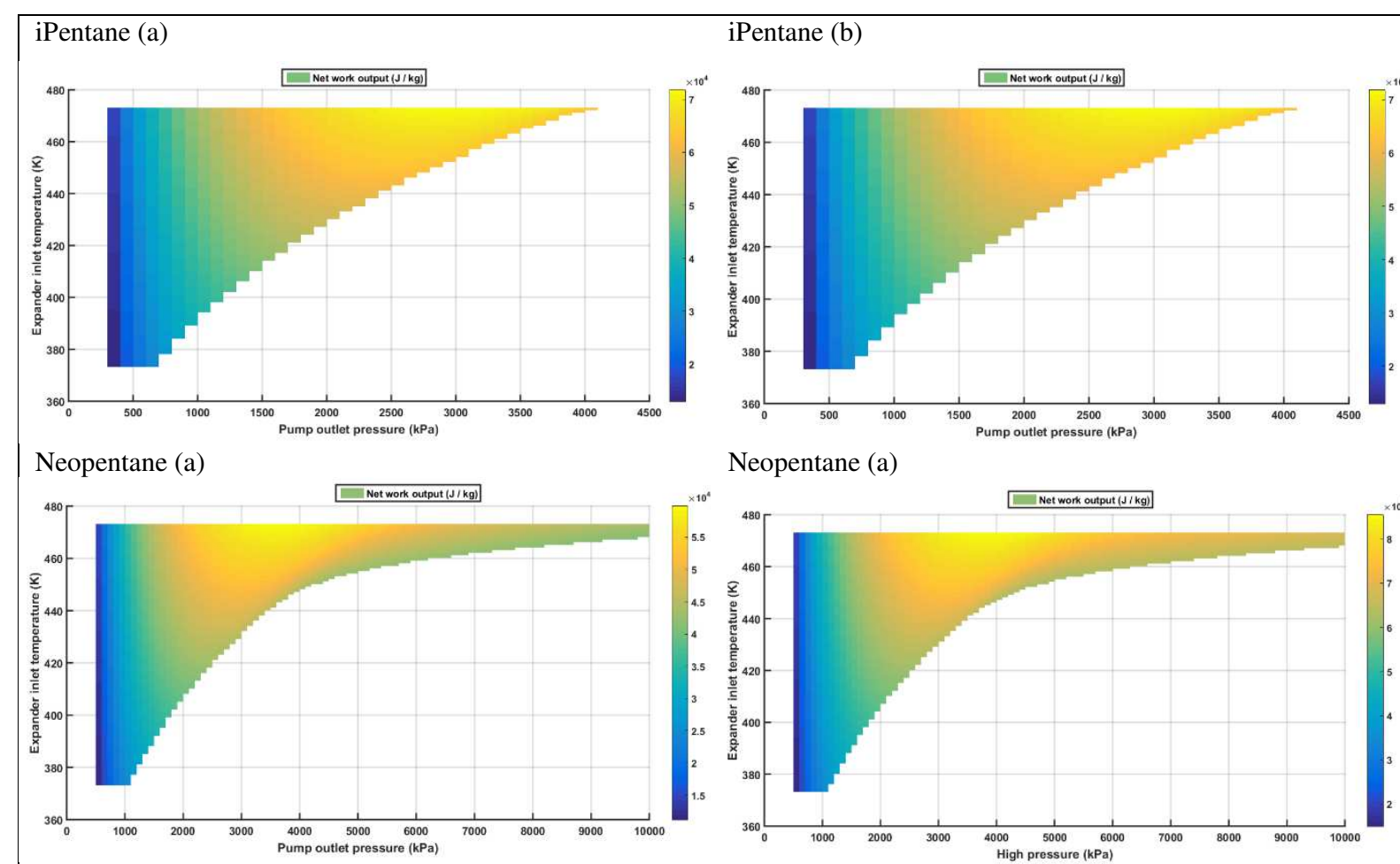

Neopentane (a)

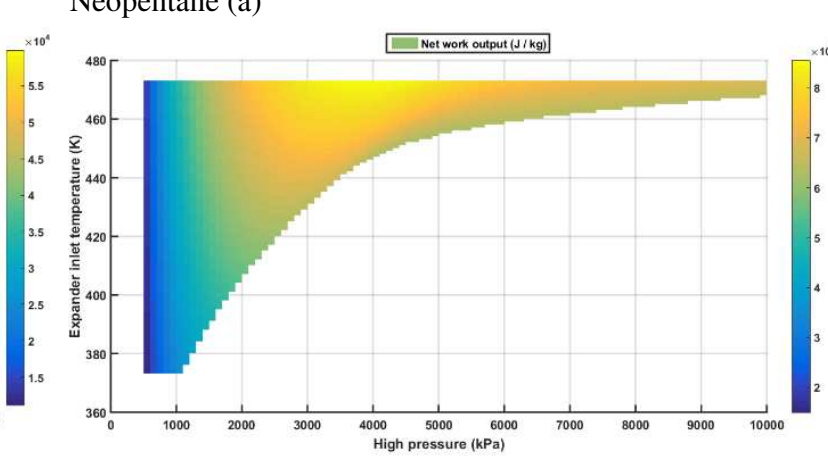

R134a (a)

R134a (a)
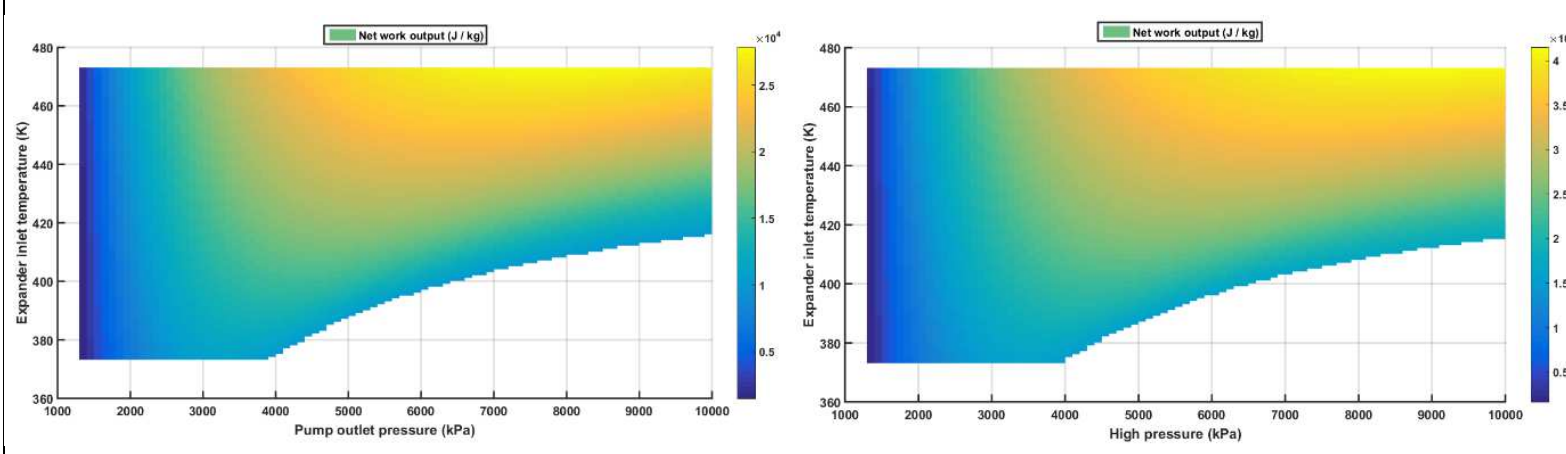

R245fa (a)

R245fa (b)
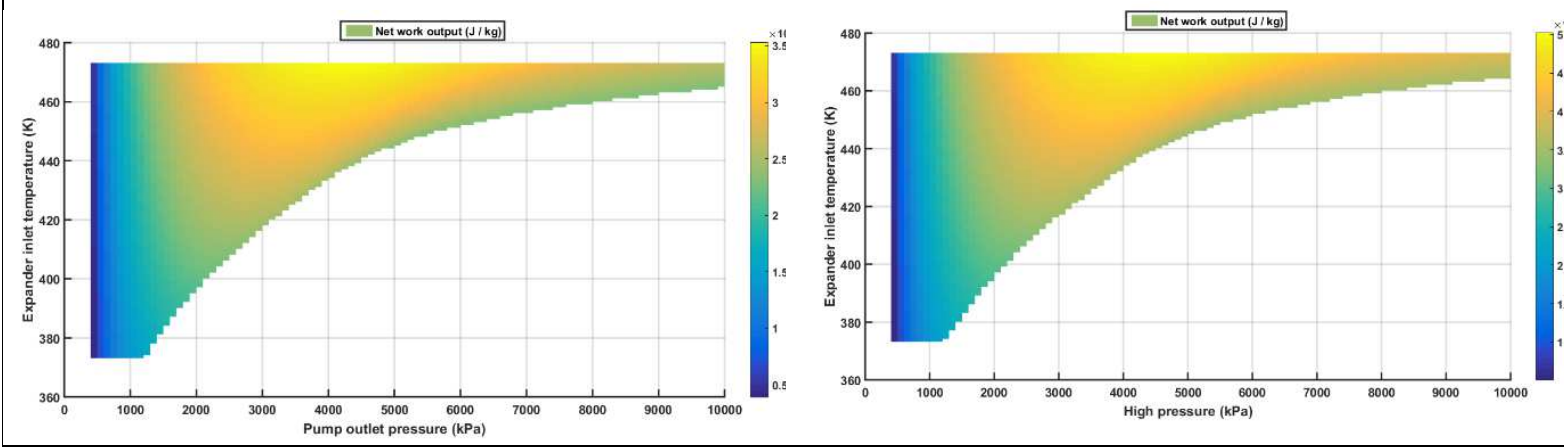


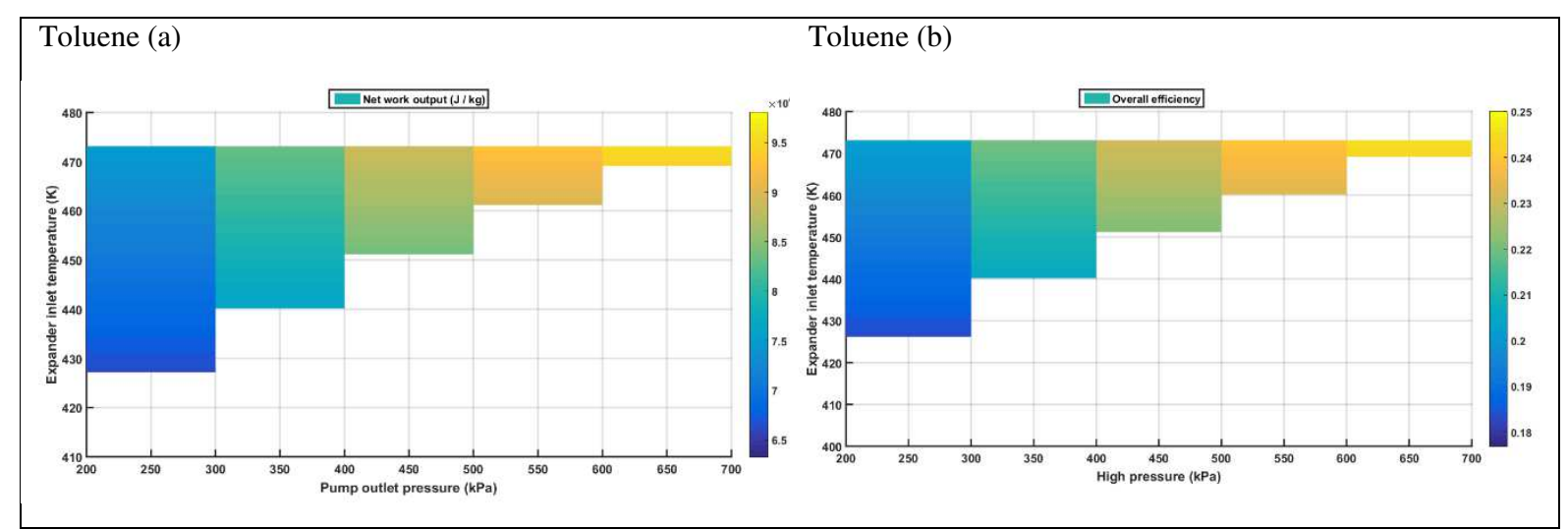

Figure 15. The net power output of the ORC and the regenerative cycle for different working fluids

\subsection{First law efficiency}

Extant literature stated that the regenerative cycle efficiency is higher when compared to the ORC cycle (Karimi and Mansouri 2018). In a regenerative cycle, using a regenerator is useful for increasing the power output; this result was compared to other studies in the literature (Roy et al. 2010). Figure 16 exhibits the comparative analysis of first law efficiency between ORC and RORC; the result has been obtained using Eqn. (25). As shown in Figure 16, it was observed that the cycle efficiency for the working fluids Butane (11.94 \%, 21.38\%), Heptane (13.67\%, 25.21\%), Hexane (13.71\%, 24.36\%), Isopentane $(12.67 \%, 22.8 \%)$, Neopentane $(11.32 \%, 22.03 \%)$ and Toluene $(16.06 \%, 25 \%)$ are comparatively higher for both ORC and the RORC systems. Further, the cycle efficiency of ORC and RORC of the R134a $(10.42 \%, 19.25 \%)$ and R245fa $(12.06 \%, 21.03 \%)$ are comparatively lower for both ORC and the RORC systems. As regards to the RORC system, all hydrocarbons performed better than CFCs as working fluids.

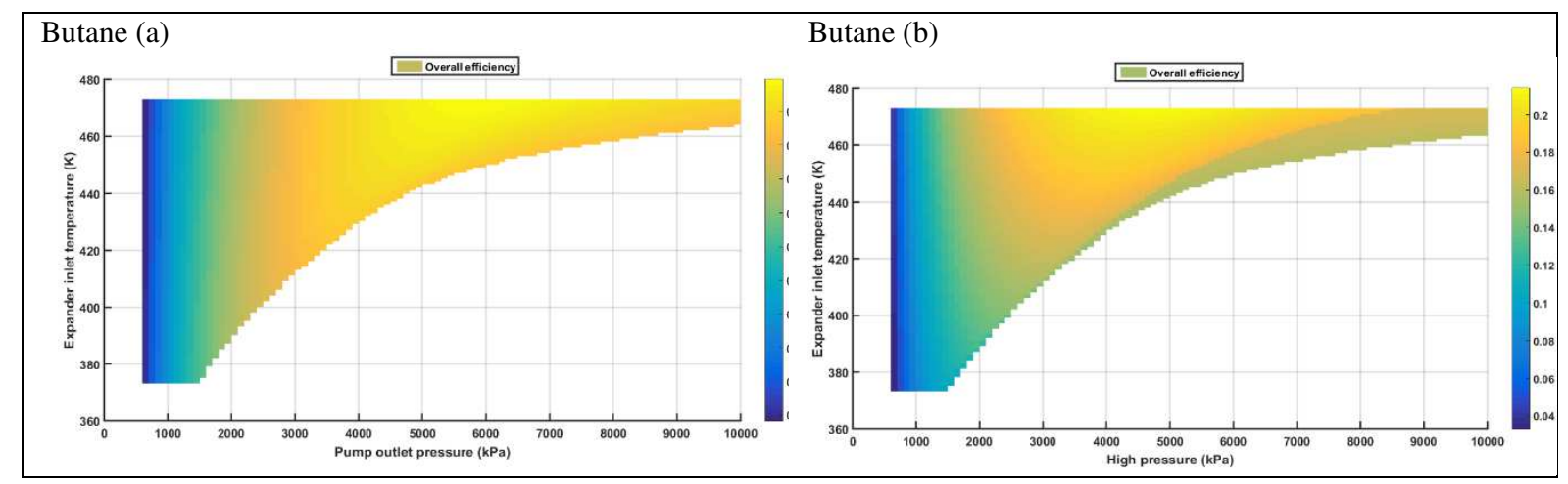



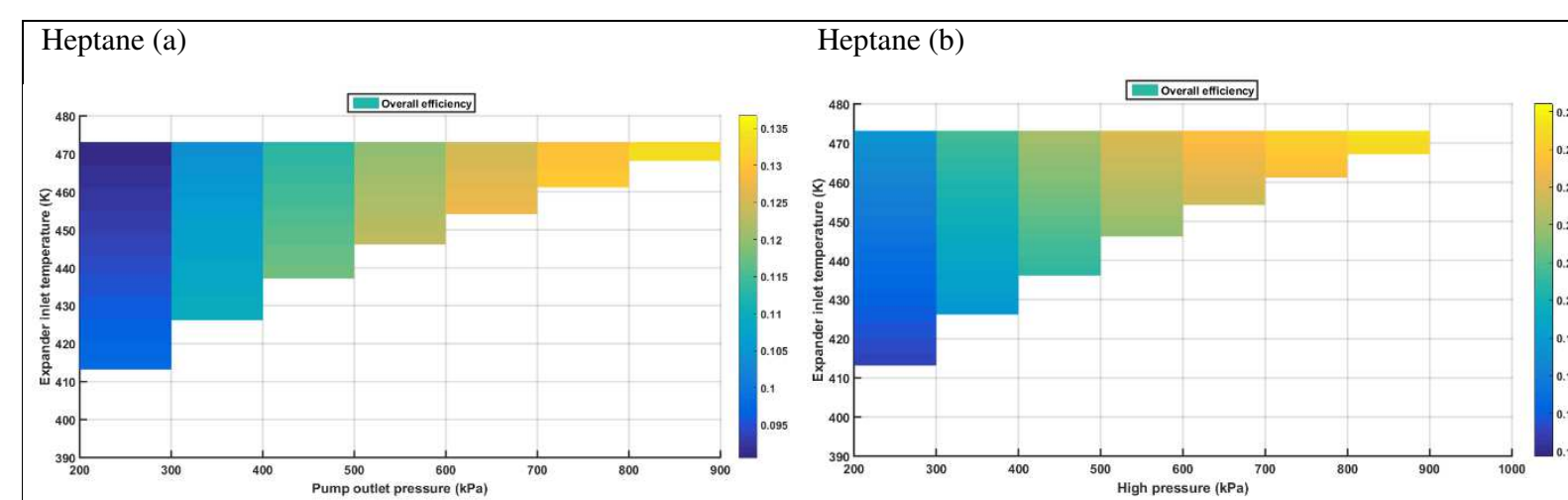

Hexane (a)

Hexane (b)
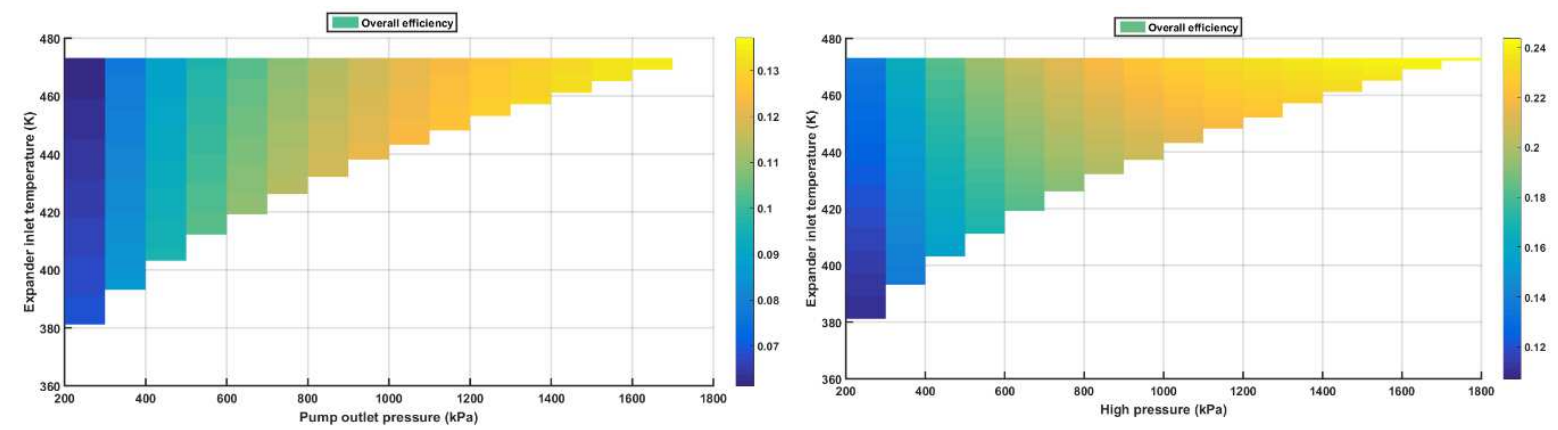

I-pentane (a)

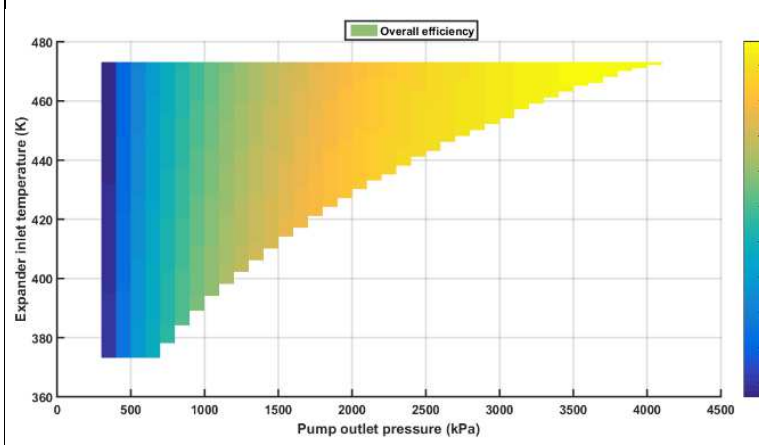

I-pentane (b)

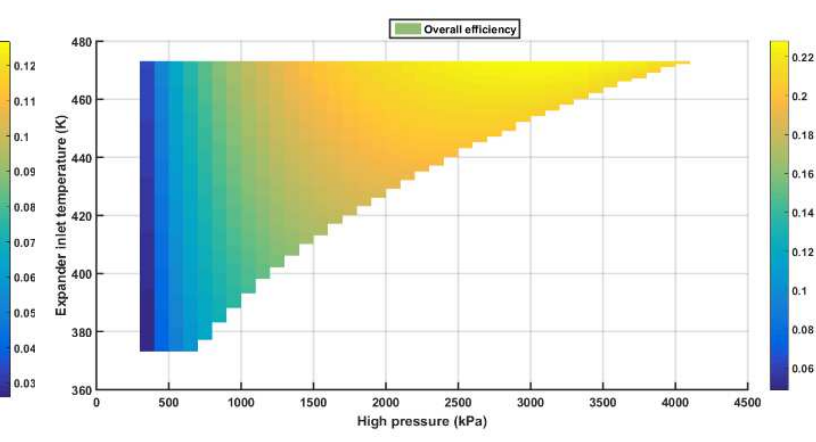

Neopentane (a)

Neopentane (b)
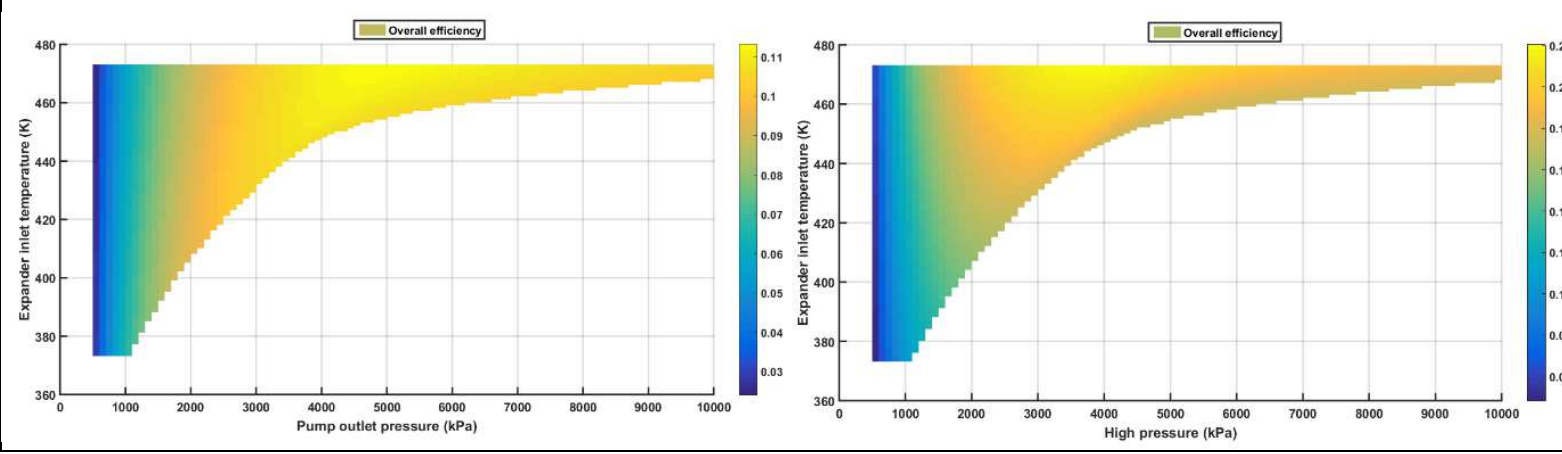

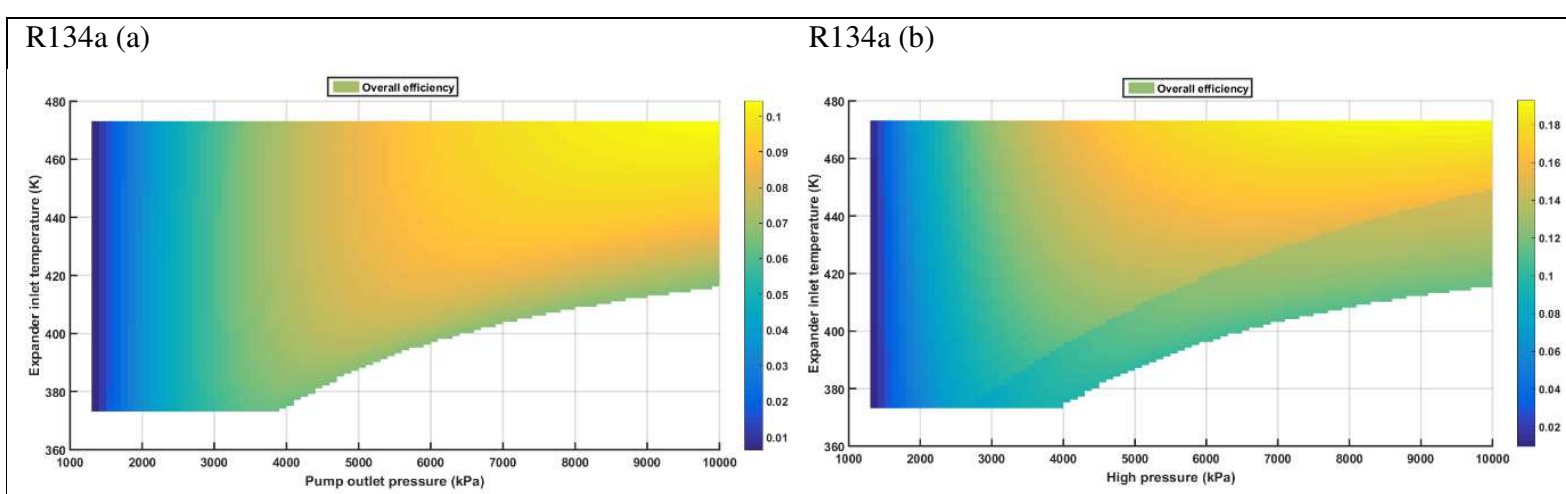

R245fa (a)

R245fa (b)
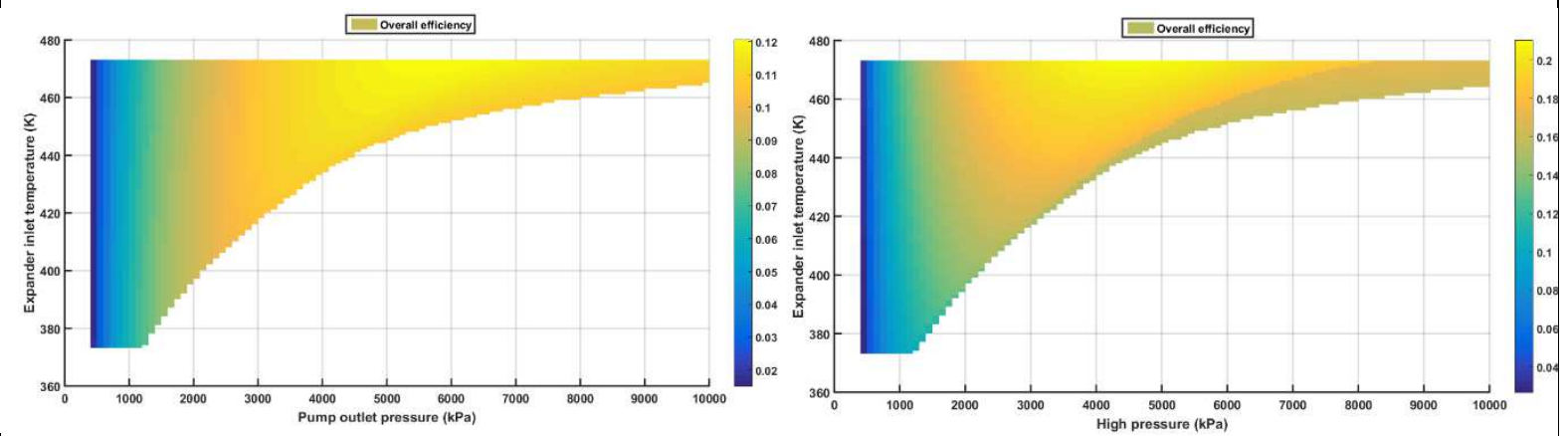

Toluene (a)

Toluene (b)
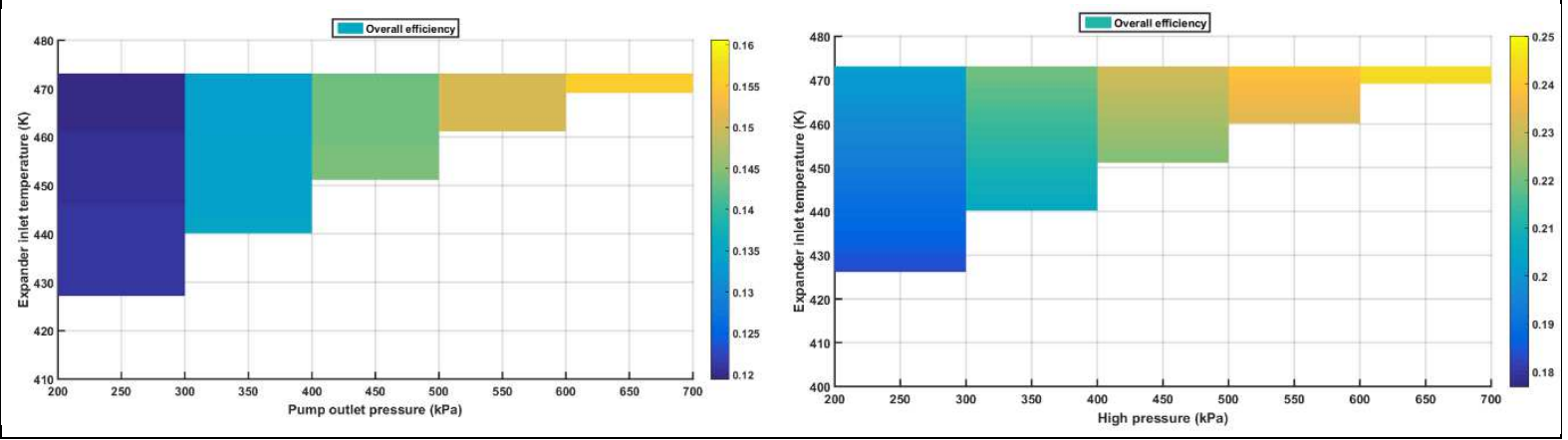

Figure 16. The First law efficiency of the ORC and the RORC cycle for different working fluids

\subsection{Exergy destruction analysis}

This section covers the assessment of the impact of different operating parameters on the exergy destruction rate for both the ORC and RORC systems. It is evident from Figure 17 (a) and (b) that the total exergy destruction is lower in the ORC system in comparison to the RORC system; this result was derived from the equation for ORC (11-14) and RORC (21-24). It may be noted that the total exergy loss is proportional to the turbine inlet temperature (TIT) for both the ORC and RORC cycles. The heat exchanger, gas turbine and condenser are the primary sources for which the exergy destruction increases with the TIT, mainly due to the heat transfer at higher temperature differences. However, the rise in the exhaust gas temperature with an increase in TIT acts as a crucial contribution to exergy destruction in the ORC. 


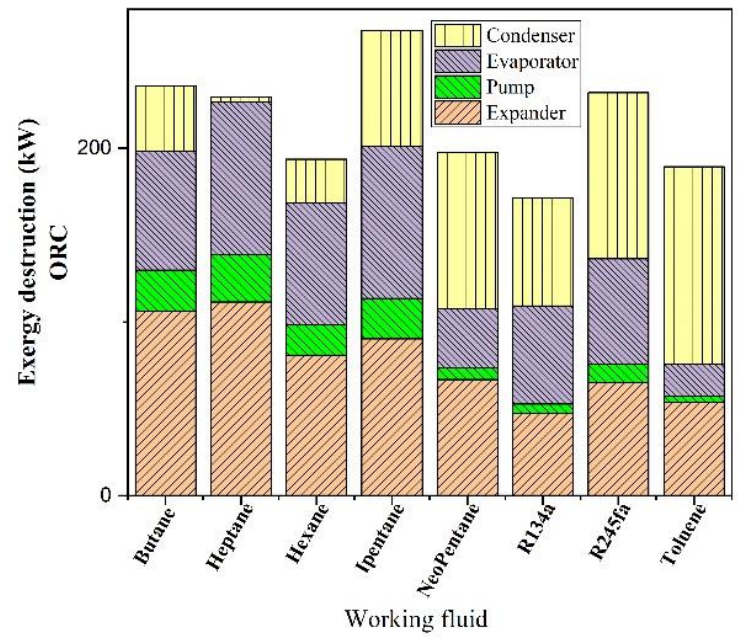

(a)

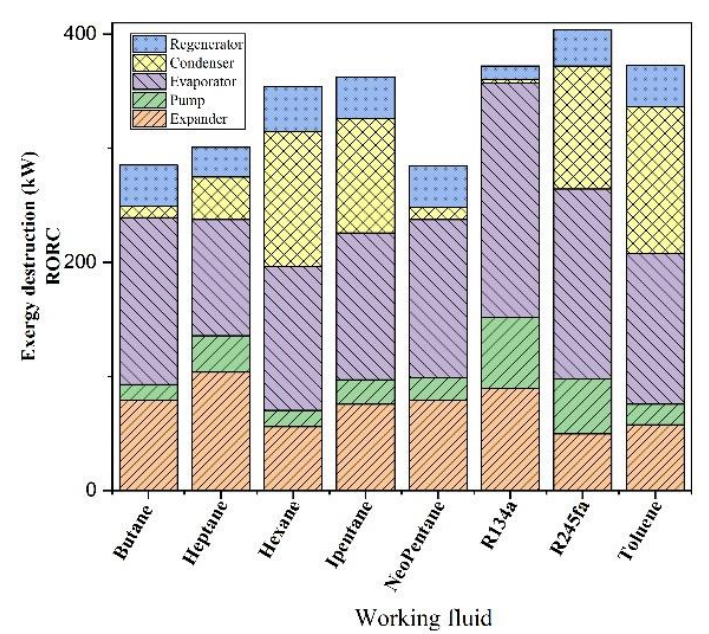

(b)

Figure 17. Exergy destruction of each equipment of ORC (a) and the RORC (b) cycle.

\subsection{Levelised cost of the system and profitability analysis}

While there is no clear linear relationship between the levelised cost and the power output, the levelised cost increases by increasing the system's total power output. An increase in the levelised cost was observed with an increase in the compressor inlet temperature due to a simultaneous hike in capital and fuel cost. The mass flow rate is also a contributing factor to the levelised cost. As the mass flow rate increases, the levelised cost also experiences a reduction. Figure 18 shows that Toluene for the ORC system has maximum levelised cost due to the maximum efficiency, power output, and mass flow rate of Toluene fluid for the ORC and RORC system. This result was further obtained from equation (35). In this work, it is clearly indicated that Butane (0.03621, 0.03959), Heptane (0.03867, 0.04006), Hexane (0.03772, 0.03549), I-pentane (0.04206, 0.03463), Neopentane (0.03837, 0.03925), R134a (0.03863, 0.03785), R245fa (0.04233, 0.03394) and Toluene $(0.04431,0.05043)$ have higher levelised cost for both ORC and RORC system. Toluene shows minimum values of levelised cost in this case study. 


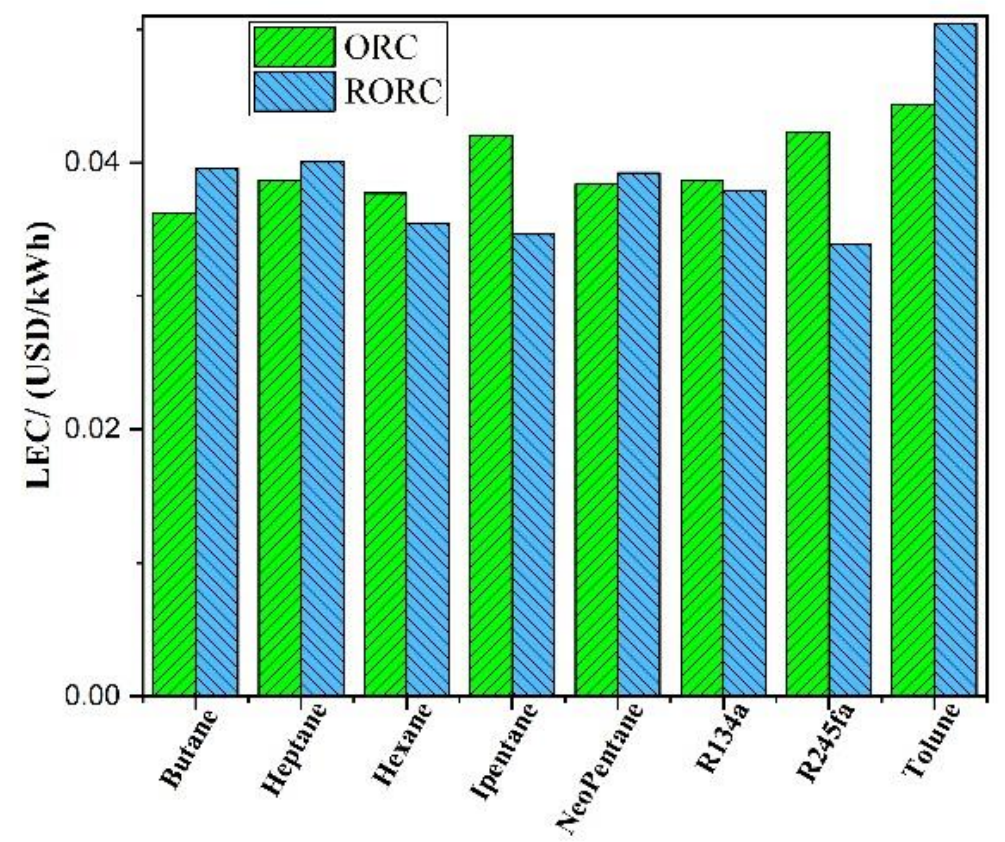

Working fluid

Figure 18. Comparison of the eight optimal working fluids for Levelised cost of the system and profitability analysis for both ORC and RORC

\subsection{Economic investment and payback period analysis}

As shown in Figure 19 (a) and (b), the total cost of the eight working fluids has been compared with their corresponding efficiency for both the ORC and RORC cycles. In the SIPP calculation, Heptane shows the highest power generation efficiency and a moderate total cost. The corresponding ranking performance of the SIPP calculation is reported in Error! Reference source not found.. Additionally, Cyclohexane is projected as the most cost-effective working fluid for the ORC cycle because its SIPP is the shortest among the 8 candidates, suggesting that it only takes $102617.46 \mathrm{~h}$ to cover the capital cost and operation and maintenance of the ORC in an ideal situation. With the shortest SIPP among the eight working fluids, Heptane appears the most cost-effective working fluid for the RORC cycle; it only takes $55581.382 \mathrm{~h}$ to cover the capital cost and operation maintenance of the RORC in an ideal situation. Compared with the RORC cycle, the ORC system consumes a higher duration to cover the primary invested value. Here, the SIPP acts as a hypothetical index in the performance ranking of the eight working fluids in an ideal and identical situation with corresponding economic and thermodynamic models. 

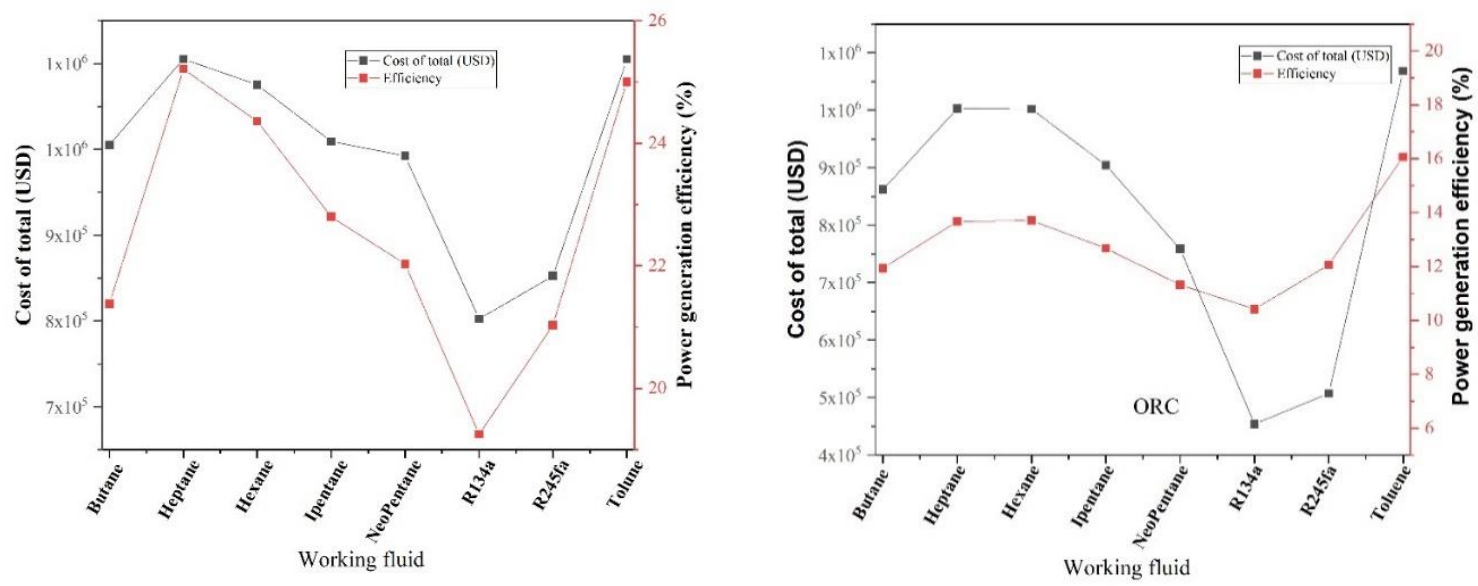

Figure 19. Total cost and power generation efficiency of eight working fluid for both ORC (a) and RORC (b)

Apart from the quality of the system efficiency and levelised cost performances, another primary concern is the economic benefit explicitly characterized by the SIPP considering the whole ORC system's total cost and profit. It was found to be a suitable measure for evaluating the effectiveness of an investment. The SIPP considers the data obtained using Eqn. (36) from the system efficiency and levelised cost. The shortest SIPP indicates the most cost-effective working fluid. To set a reasonable criterion for selecting the most cost-effective working fluid, the entire ORC system's SIPP study using the system efficiency and levelised cost of the optimal compromise solutions for the eight candidates was taken under consideration.

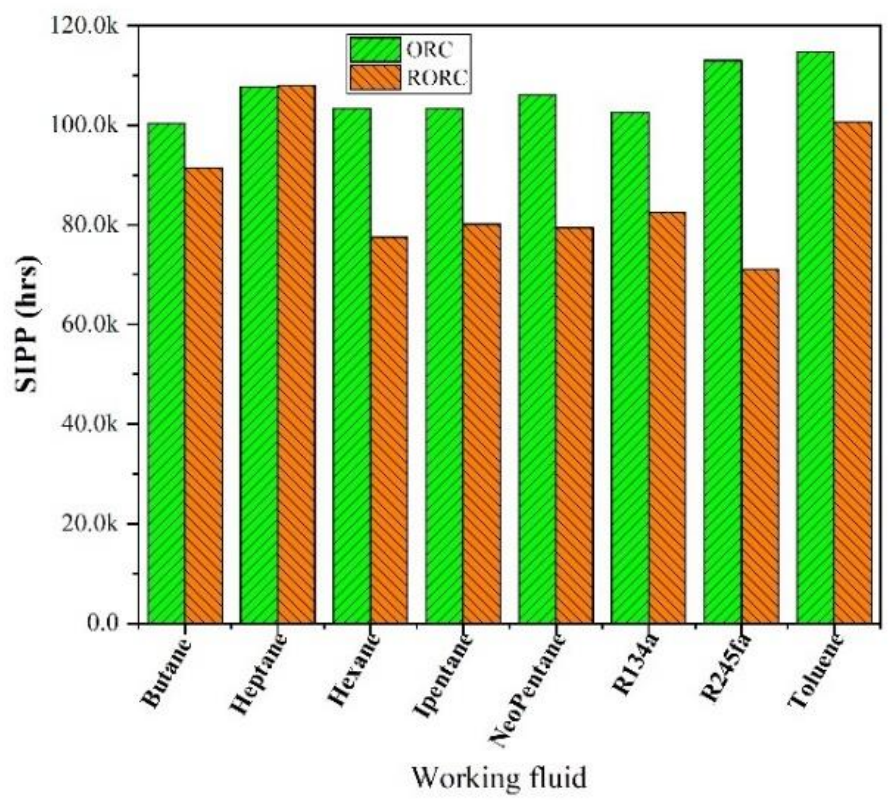

Figure 20. SIPP Ranking for eight working fluid for both ORC and RORC 
In the SIPP calculation, Toluene is shown to offer the best power generation efficiency and a moderate overall expense, with SIPP values among the fifty-two contestants of $14360.9 \mathrm{~h}$ and $24039.46 \mathrm{~h}$, respectively. With the shortest SIPP of the 47 working fluids, Toluene appears as the most cost-effective working fluid. In order to cover the primary value expended, the ORC system uses a more extended duration relative to the RORC. The SIPP acts as a hypothetical index to determine the utility ranking of the fifty-two operating fluids in an optimal and comparable situation with the related economic and thermodynamic models. These findings are obtained from Eqn (21). The optimal consensus solutions were chosen using a standardized weighted ranking compared with the best-performing fifty-two working fluids shown in Figure 21.
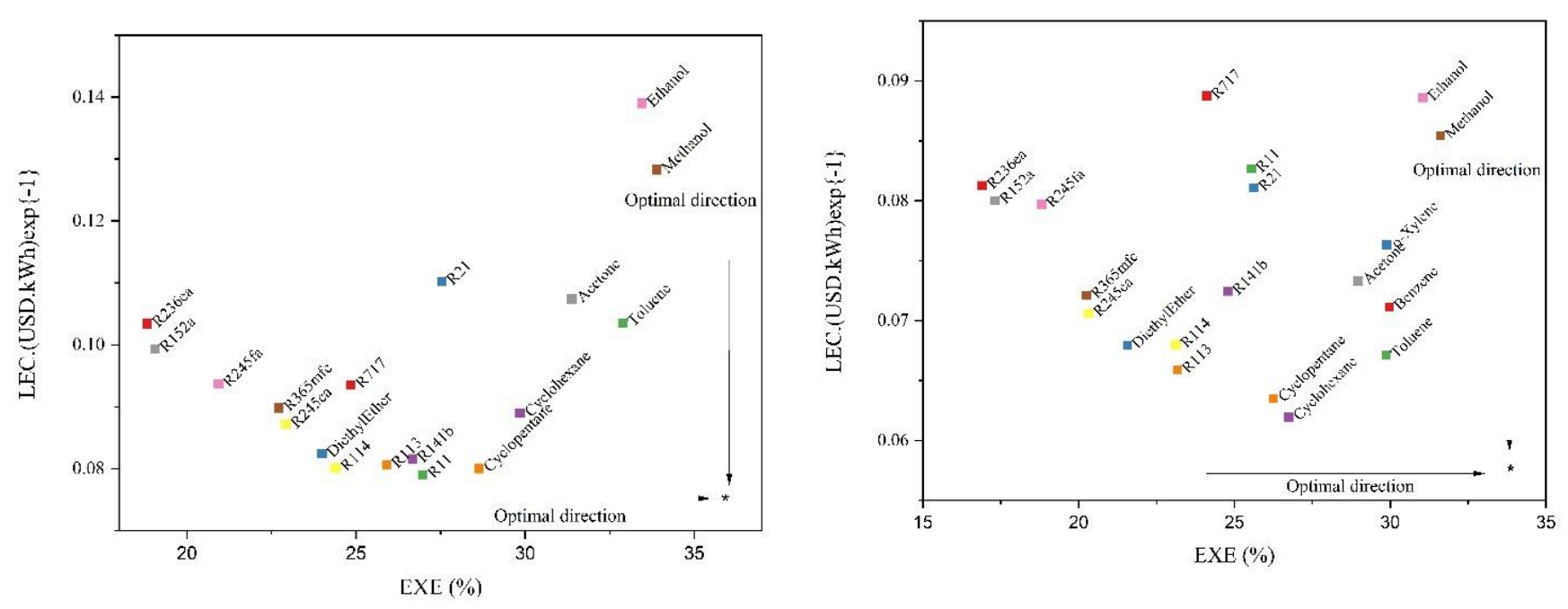

Figure 21. Comparison of ORC and RORC with different working fluids of optimal compromise solutions. (a) ORC and (b) RORC

\section{Conclusion and discussion:}

The key technologies that can be used today are listed and compared in this paper for their use as waste heat recovery systems. The highest reasonable investment expense is calculated for each technology and compared with the actual investment cost, based on the service hour. Our analysis has looked to estimate the thermal energy recoverable part of waste heat in India's coke oven plant. In order to validate the Aspen Hysys ${ }^{\circledR}$, V9 simulator, at first, we executed a steady-state simulation for the ORC system using working fluid R123. The energy efficiency and the heat input data have matched very closely with the experimental data. Characteristics equations for all the equipment from available reports have been successfully included in the Aspen Hysys ${ }^{\circledR}$, V9 simulator. We have noticed minimal deviations between experimental and simulation data, and its correlation with existing literature reveals that it is acceptable. 
Finally, low-grade waste heat recovery technology has a significant potential to be vibrant in the energy sector; we have looked into the different technical aspects and corresponding challenges. Various working fluids have also been considered to compare multiple characteristic parameters like first law efficiency, exergy efficiency, purchase equipment cost, and fixed investment payback period. This comparative study indicates that the regenerative cycle is the most suitable technique for low grade waste heat recovery in industrial sectors; additionally, we found that toluene is the most suitable working fluid based on this particular case study.

This study focused on the power generation potential from low-grade waste heat in an Indian coke oven plant. No such studies have been found to estimate waste heat potential in energy-intensive industries. In the future, this method could be employed to assess other energy-intensive sectors, such as iron and steel, cement, pulp and paper, caustic soda, and glass industries. Nevertheless, we need to mention that some government reports have covered energy consumption and the process within these energyintensive sectors; but there is a severe lack of plant-level information regarding waste heat. For industry and vehicle motors, variations and intermittency of thermal strength are inherent. Stream management can ensure safe and near to optimum point operations by bypassing any of the streams in the evaporator. In order to optimize the quantity of thermal power recovered while reducing energy losses, new revolutionary technologies can be further developed.

Future research could assess waste heat and its potential conversion to electricity in all pre-discussed energy-intensive industries. This study for the first time provides a calculation of the thermal energy potential from the low-temperature waste heat in the coke-oven industry. These types of studies will assist in achieving the development of sustainable urbanization and a low-carbon footprint. Finally, an acceptable policy is desired to incorporate waste heat utilization in the world's energy and climate goals.

\section{Declarations}

\section{Funding}

No funding was received for conducting this study.

\section{Conflict of interest}

On behalf of all authors, the corresponding author states that there is no conflict of interest.

\section{Data Availability Statement}

Data sharing not applicable to this article as no datasets were generated or analyzed during the current study. 


\section{Financial interests}

The authors have no relevant financial or non-financial interests to disclose.

\section{References}

Acar C, Dincer I (2018) The potential role of hydrogen as a sustainable transportation fuel to combat global warming. Int J Hydrogen Energy. https://doi.org/10.1016/j.ijhydene.2018.10.149

Agamah SU, Ekonomou L (2017) Energy storage system scheduling for peak demand reduction using evolutionary combinatorial optimisation. Sustain Energy Technol Assessments 23:73-82. https://doi.org/10.1016/j.seta.2017.08.003

Bandyopadhyay S, Desai NB (2015) Cost optimal energy sector planning: A Pinch Analysis approach. J Clean Prod 136:246-253. https://doi.org/10.1016/j.jclepro.2016.03.077

Dai Y, Wang M, Li M, et al (2013) Multi-objective optimization of an organic Rankine cycle (ORC) for low grade waste heat recovery using evolutionary algorithm. Energy Convers Manag 71:146-158. https://doi.org/10.1016/j.enconman.2013.03.028

Deethayat T, Asanakham A, Kiatsiriroat T (2016) Performance analysis of low temperature organic Rankine cycle with zeotropic refrigerant by Figure of Merit (FOM). Energy 96:96-102. https://doi.org/10.1016/j.energy.2015.12.047

Desai NB, Bandyopadhyay S (2015a) Integration of parabolic trough and linear Fresnel collectors for optimum design of concentrating solar thermal power plant. Clean Technol Environ Policy 17:1945-1961. https://doi.org/10.1007/s10098-015-0918-9

Desai NB, Bandyopadhyay S (2016) Thermo-economic analysis and selection of working fluid for solar organic Rankine cycle. Appl Therm Eng 95:471-481. https://doi.org/10.1016/j.applthermaleng.2015.11.018

Desai NB, Bandyopadhyay S (2015b) Optimization of concentrating solar thermal power plant based on parabolic trough collector. J Clean Prod 89:262-271. https://doi.org/10.1016/j.jclepro.2014.10.097

Ding Y, Tong L, Zhang P, et al (2016) Chapter 9 - Liquid Air Energy Storage. In: Letcher TM (ed) Storing Energy. Elsevier, Oxford, pp 167-181

Dutta R, Ghosh P, Chowdhury K (2017a) Process configuration of Liquid-nitrogen Energy Storage System (LESS) for maximum turnaround efficiency. Cryogenics (Guildf) 88:132-142. https://doi.org/10.1016/j.cryogenics.2017.10.003 
Dutta R, Ghosh P, Chowdhury K (2017b) Process configuration of Liquid-nitrogen Energy Storage System (LESS) for maximum turnaround efficiency. Cryogenics (Guildf) 88:132-142. https://doi.org/https://doi.org/10.1016/j.cryogenics.2017.10.003

Dutta R, Ghosh P, Chowdhury K (2011) Customization and validation of a commercial process simulator for dynamic simulation of Helium lique fi er. Energy 36:3204-3214. https://doi.org/10.1016/j.energy.2011.03.009

Emre M, Dincer I (2017) Development of an integrated hybrid solar thermal power system with thermoelectric generator for desalination and power production. DES 404:59-71. https://doi.org/10.1016/j.desal.2016.10.016

European Commission (2018) Paris Agreement

Henriques J, Catarino J (2016) Motivating towards energy efficiency in small and medium enterprises. J Clean Prod 139:42-50. https://doi.org/10.1016/j.jclepro.2016.08.026

IIT Kanpur KASLPWBEAL EAL (2020). In: Aver. Syst. Load Profile West Bengal, Energy Anal. Lab, IIT Kanpur, Kanpur. https://eal.iitk.ac.in/download/system_load_profile.php. Accessed 18 Nov 2020

Islam S, Dincer I, Yilbas BS (2018) Development of a novel solar-based integrated system for desalination with heat recovery. Appl Therm Eng 129:1618-1633. https://doi.org/10.1016/j.applthermaleng.2017.09.028

Jiménez-Arreola M, Pili R, Dal Magro F, et al (2018) Thermal power fluctuations in waste heat to power systems: An overview on the challenges and current solutions. Appl Therm Eng 134:576584. https://doi.org/10.1016/j.applthermaleng.2018.02.033

Jing Li (2011) Structural Optimization and Experimental Investigation of the Organic Rankine Cycle for Solar Thermal Power Generation

Kalyanmoy Deb, Amrit Pratap, Sameer Agarwal TM (2002) A Fast and Elitist Multiobjective Genetic Algorithm: NSGA-II. 182 Ieee Trans Evol Comput 6:182-197. https://doi.org/10.1109/4235.996017

Karimi S, Mansouri S (2018) A comparative profitability study of geothermal electricity production in developed and developing countries: Exergoeconomic analysis and optimization of different ORC configurations. Renew Energy 115:600-619. https://doi.org/10.1016/j.renene.2017.08.098

Krishna B, Basab S (2016) Utilization of low-grade waste heat-to-e.nergy technologies and policy in Indian industrial sector : a review. Clean Technol Environ Policy. 
https://doi.org/10.1007/s10098-016-1248-2

Liu Z, Karimi IA (2018) Simulating combined cycle gas turbine power plants in Aspen HYSYS. Energy Convers Manag 171:1213-1225. https://doi.org/10.1016/j.enconman.2018.06.049

Markides CN (2015) Low-Concentration Solar-Power Systems Based on Organic Rankine Cycles for Distributed-Scale Applications: Overview and Further Developments. Front Energy Res 3:1-16. https://doi.org/10.3389/fenrg.2015.00047

Mignard D (2014) Correlating the chemical engineering plant cost index with macro-economic indicators. Chem Eng Res Des 92:285-294. https://doi.org/10.1016/j.cherd.2013.07.022

Minea V (2014) Power generation with ORC machines using low-grade waste heat or renewable energy. Appl Therm Eng 69:143-154. https://doi.org/10.1016/j.applthermaleng.2014.04.054

Morgan R, Nelmes S, Gibson E, Brett G (2015) Liquid air energy storage - Analysis and first results from a pilot scale demonstration plant. Appl Energy 137:845-853. https://doi.org/10.1016/j.apenergy.2014.0

National Productivity Council I (2017) GHG-Manual-Thermal-Power-Plant. https://www.npcindia.gov.in/NPC/User/index. Accessed 6 Jul 2020

Özahi E, Tozlu A, Abuşoğlu A (2018) Thermoeconomic multi-objective optimization of an organic Rankine cycle (ORC) adapted to an existing solid waste power plant. Energy Convers Manag 168:308-319. https://doi.org/10.1016/j.enconman.2018.04.103

Parrondo AJ, Villar A, Jose J (2012) Waste-to-energy technologies in continuous process industries. 29-39. https://doi.org/10.1007/s10098-011-0385-x

Preißinger M, Schatz S, Vogl A, et al (2016) Thermoeconomic analysis of configuration methods for modular Organic Rankine Cycle units in low-temperature applications. 127:25-34. https://doi.org/10.1016/j.enconman.2016.08.092

Priya GSK, Bandyopadhyay S (2013) Emission constrained power system planning : a pinch analysis based study of Indian electricity sector. 771-782. https://doi.org/10.1007/s10098-012-0541-y

R. Turton, R.C. Bailie WBW and JAS (2013) Analysis, synthesis, and design of chemical processes

Rezvani A, Gandomkar M, Izadbakhsh M, Ahmadi A (2015) Environmental / economic scheduling of a micro-grid with renewable energy resources. J Clean Prod 87:216-226. https://doi.org/10.1016/j.jclepro.2014.09.088

Roy JP, Mishra MK, Misra A (2011a) Performance analysis of an Organic Rankine Cycle with 
superheating under different heat source temperature conditions. Appl Energy 88:2995-3004. https://doi.org/10.1016/j.apenergy.2011.02.042

Roy JP, Mishra MK, Misra A (2010) Parametric optimization and performance analysis of a waste heat recovery system using Organic Rankine Cycle. Energy 35:5049-5062. https://doi.org/10.1016/j.energy.2010.08.013

Roy JP, Mishra MK, Misra A (2011b) Performance analysis of an Organic Rankine Cycle with superheating under different heat source temperature conditions. Appl Energy 88:2995-3004. https://doi.org/10.1016/j.apenergy.2011.02.042

Sadeghi M, Kalantar M (2015) The analysis of the effects of clean technologies from economic point of view. J Clean Prod 102:394-407. https://doi.org/10.1016/j.jclepro.2015.04.042

Saha BK, Chakraborty B, Dutta R (2020) Estimation of waste heat and its recovery potential from energy-intensive industries. Clean Technol Environ Policy 22:1795-1814. https://doi.org/10.1007/s10098-020-01919-7

Saha BK, Chakraborty B, Pundeer P (2019) Thermodynamic and thermo economic analysis of organic rankine cycle with multi-objective optimization for working fluid selection with lowtemperature waste sources in the Indian industry. 5th Int Semin ORC Power Syst 5-12

Sarkar J, Bhattacharyya S (2015a) Potential of organic Rankine cycle technology in India: Working fluid selection and feasibility study. Energy 90:1618-1625. https://doi.org/10.1016/j.energy.2015.07.001

Sarkar J, Bhattacharyya S (2015b) Potential of organic Rankine cycle technology in India : Working fl uid selection and feasibility study. Energy 90:1618-1625. https://doi.org/10.1016/j.energy.2015.07.001

Shin-Ichi Inage (2009) Prospects for Energy Storage in Decarbonised Power Grids WO R K I N G PA P E R. 92

Sikdar SK, Sengupta D, Mukherjee R (2017) Measuring Progress Towards Sustainability. Springer International Publishing

Tafone A, Borri E, Comodi G, et al (2017) Preliminary assessment of waste heat recovery solution (ORC) to enhance the performance of Liquid Air Energy Storage system. In: Energy Procedia. Elsevier Ltd, pp 3609-3616

The MathWorks Inc 2018 (2018) MATLAB 
Thomas RJ (2012) Exergy approach in designing large-scale helium liquefiers. Indian Institute of Technology Kharagpur, India

Xie C, Li Y, Ding Y, Radcliffe J (2019) Evaluating Levelized Cost of Storage (LCOS) Based on Price Arbitrage Operations: with Liquid Air Energy Storage (LAES) as an Example. Energy Procedia 158:4852-4860. https://doi.org/https://doi.org/10.1016/j.egypro.2019.01.708

Zhang Z, Zhang X, Bai H, et al (2018) Multi-objective optimisation and fast decision-making method for working fluid selection in organic Rankine cycle with low-temperature waste heat source in industry. Energy Convers Manag 172:200-211. https://doi.org/10.1016/j.enconman.2018.07.021 


\section{Supplementary Files}

This is a list of supplementary files associated with this preprint. Click to download.

- GraphicalAbstract.docx

- SupplementaryMaterial.docx 